\title{
A MIXED METHODS STUDY OF A STATISTICS PATHWAY FOR COMMUNITY COLLEGE STUDENTS PLACED INTO DEVELOPMENTAL MATHEMATICS
}

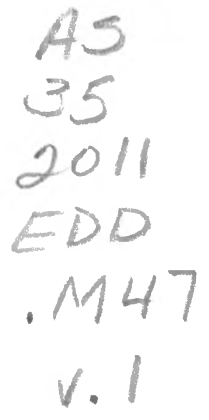

A dissertation submitted to the faculty of San Francisco State University

In partial fulfillment of

The Requirements for

The Degree

Doctor of Education

In

Educational Leadership

by

Pamela Marie Mery

San Francisco, California

December 2011 
Copyright $(\mathbb{C}$ by

Pamela Marie Mery

2011 


\section{CERTIFICATION OF APPROVAL}

I certify that I have read A Mixed Methods Study of a Statistics Pathway for Community College Students Placed into Developmental Mathematics by Pamela Marie Mery, and that in my opinion this work meets the criteria for approving a dissertation submitted in partial fulfillment of the requirements for the degree: Doctor of Education in Educational Leadership at San Francisco State University.

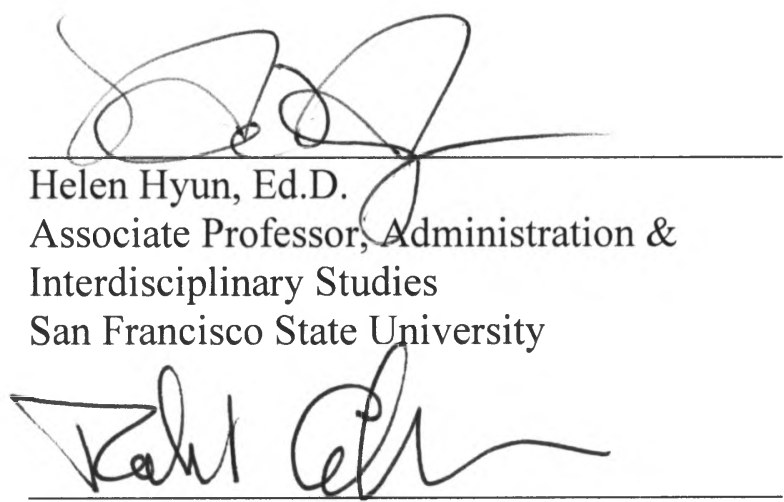

Robert Gabriner, Ed.D.

Professor, Educational Leadership Director, Educational Leadership Program

San Francisco State University

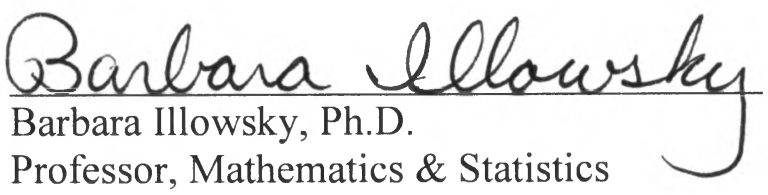

De Anza College

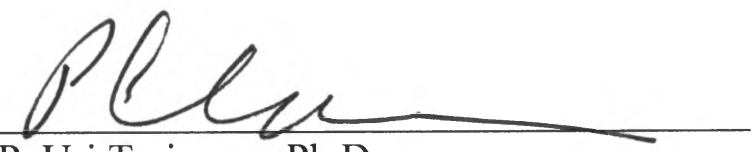

P. Uri Treisman, Ph.D.

Professor, Mathematics

Director, Charles A. Dana Center

University of Texas at Austin 


\title{
A MIXED METHODS STUDY OF A STATISTICS PATHWAY FOR COMMUNITY COLLEGE STUDENTS PLACED INTO DEVELOPMENTAL MATHEMATICS
}

\author{
Pamela Mery \\ San Francisco State University \\ 2011
}

Low completion rates for developmental mathematics sequences and in gateway mathematics courses prevent a majority of community college students from achieving transfer goals. This explanatory mixed methods case study examined an open-entry, accelerated, two-course mathematics sequence culminating in transfer-level statistics. Of the beginning cohort, nearly all of whom were Latino or African American, $86 \%$ successfully completed the sequence and performed well on questions from the nationally-normed CAOS exam. Student interviewees repeatedly attributed their success to growth mindset, consistent with their high scores on the Adult Dispositional Hope Scale. Observations substantiated ways that classroom interactions supported and reinforced students' new sense of competency regarding mathematics. With regard to contextualization, students' motivation seemed to derive from challenging statistics content rather than direct applicability or relevance. These findings have important implications for educational equity since lengthy developmental mathematics sequences have a disproportionately negative impact on underprepared students of color.

I certify that the Abstract is a correct representation of the content of this dissertation.

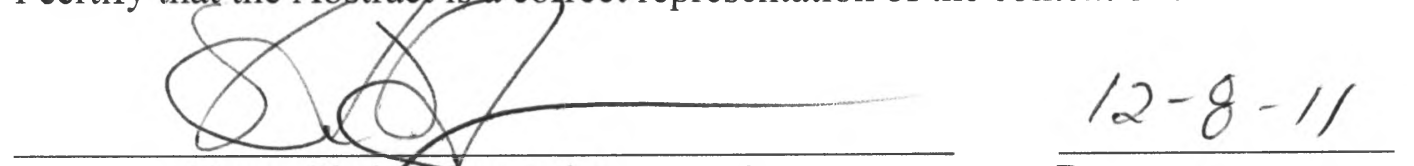

Dr. Helen Hyun, Chai, Dissertation Committee

Date 


\section{ACKNOWLEDGEMENTS}

My sincere gratitude goes to my advisor and chair, Dr. Helen Hyun, for her patience and steadfast encouragement. Many thanks to Dr. Uri Treisman whose broad knowledge and incisive questions immeasurably enriched this endeavor. Thanks as well to Dr. Barbara Illowsky for her interest in precision and for her confidence in me. And to Dr. Robert Gabriner with whom I first investigated mathematics success rates years ago, thank you for encouraging me to look deeper.

To my incredible spouse, Adrina Phipps, thank you for cheering me on, for keeping me

focused, and for sustaining me throughout the entire process. To family, friends, and colleagues who supported me during this work: thank you. Special thanks go to my parents Milton and Helene Mery who taught me to value learning and service to community; to Drs. Leslie Minot, Theresa Tensuan-Eli, and Annette Daoud who showed me it could be done; and to Sensei Keiko Fukuda who taught me what it means to love your students.

Finally, to the anonymous instructor whose classroom is the subject of this study, your graciousness, vulnerability, and dedication constantly humbled and inspired me. And to the students who willingly shared their stories with me: thank you. This dissertation represents a small fraction of what I learned from you and what I carry forward with me. 


\section{TABLE OF CONTENTS}

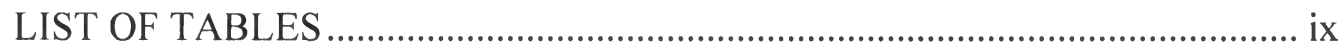

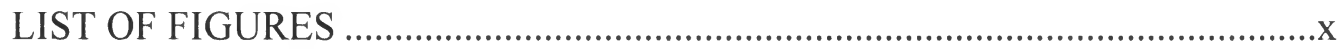

LIST OF APPENDICES ….......................................................................

Chapter One: Purpose of the Study .................................................................

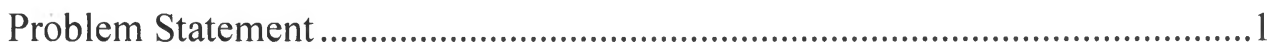

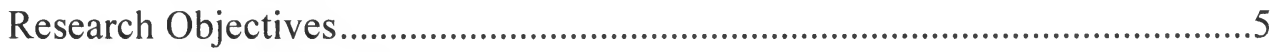

Quantitative Hypotheses ..........................................................................5

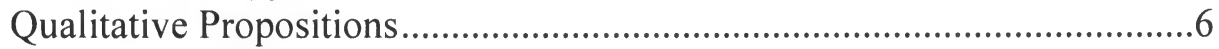

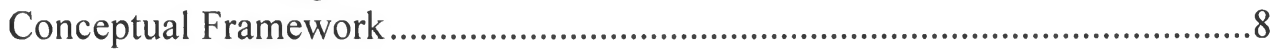

Key Constructs and Operational Definitions ................................................13

Delimitations and Scope of the Study ........................................................15

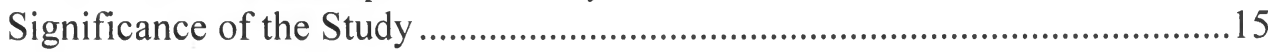

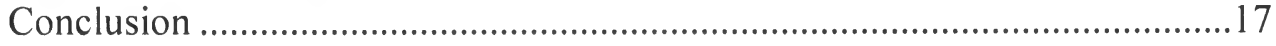

Organization of the Dissertation ...........................................................18

Chapter Two: Literature Review ........................................................................19

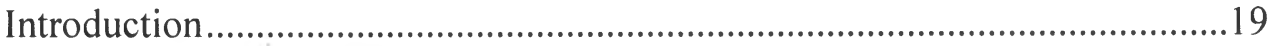

Scope and Search Criteria .....................................................................23

Structure of Review ........................................................................25

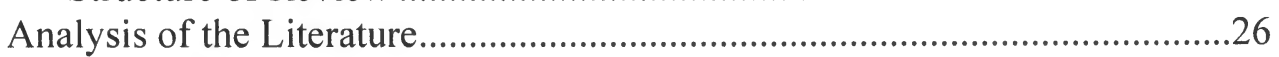

Math as Catalyst or Barrier ...................................................................26

The Climb to College-Level Math..........................................................29

Studies of Special Populations and Developmental Mathematics .............33

Improving Mathematics Success Rates in Community Colleges ..............36

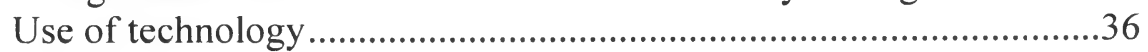

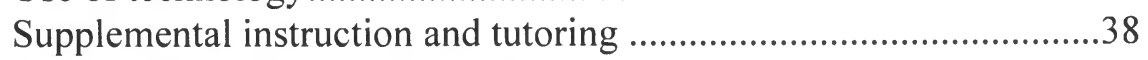

Structural changes to the sequence..................................................40

Contextual learning approaches .......................................................42

Cultural relevance, social justice, and statistics ...............................46

Learning Implications of Growth Mindset / Incrementalism ...................47

Conclusions and Needed Research ...........................................................5. 52

Implications for Research ...............................................................55 


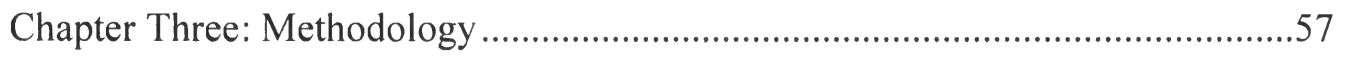

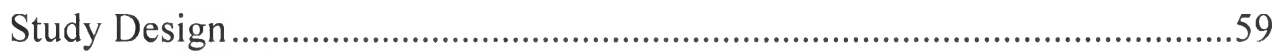

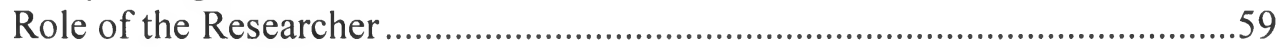

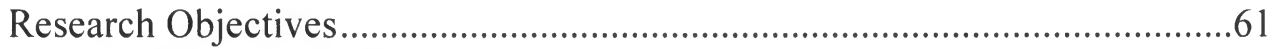

Quantitative Hypotheses .....................................................................61

Qualitative Propositions.....................................................................63

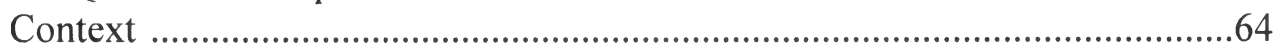

Student Demographics Pertaining to Quantitative Analysis............................66

Participant Selection for Qualitative Analysis .............................................66

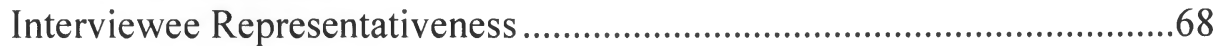

Latina/o Group and Outlier ..................................................................68

African American Group ..........................................................................69

Ethics and Protection of Human Subjects.......................................................72

Data Collection and Instrumentation ..........................................................72

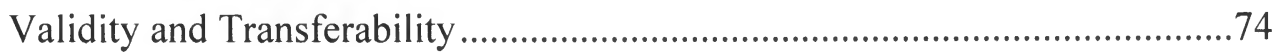

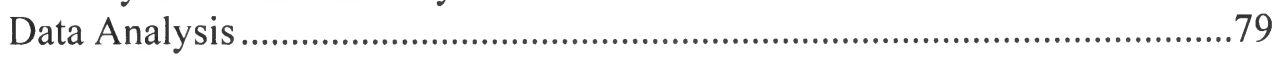

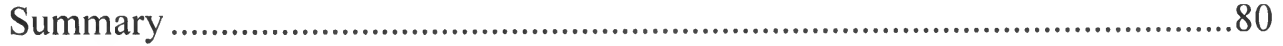

Chapter Four: Quantitative Findings …..............................................................82

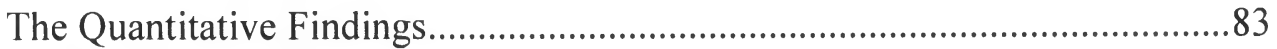

Pre-Statistics Course Success for Initial Cohort ......................................86

Statistics Course Success for Initial Cohort ..........................................88

Two-Course Sequence Success for Initial Cohort ...................................90

CAOS Results at Sequence Culmination .................................................93

Hope Scale Results for Interviewees .....................................................98

Summary and Synthesis ........................................................................100

Chapter Five: Qualitative Themes for Math Attitudes and Growth Mindset ......103

Initial Mathematics Attitudes and Backgrounds...........................................104

Best Math Experiences ......................................................................105

Worst Math Experiences.....................................................................108

Fixed Mindset and Limited Effective Encouragement ............................110

Perceived Power of Growth Mindset ............................................................114

Critical Importance of Growth Mindset..................................................115

Caring about Learning ........................................................................122

Involving Each Student......................................................................127

Thinking Differently about Errors and Risk-Taking ...............................137

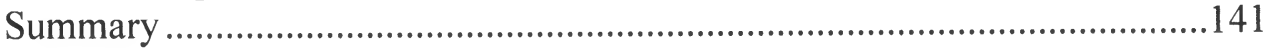


Chapter Six: Student Motivation and Classroom Observations

Motivation through Intellectual Engagement ............................................145

Overwhelming Enthusiasm Yet Enduring Pragmatism .......................... 146

Enduring pragmatism and detracking............................................148

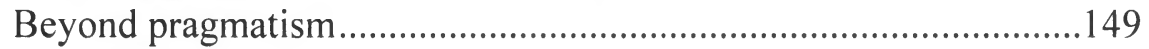

Limited Views on Applicability........................................................150

Direct challenges to utility .........................................................151

Breakthroughs in understanding leading to usage ............................153

A classroom project with everyday relevance..................................154

Summary of applicability ..............................................................156

Deep Engagement with Challenging Material ........................................157

Statistics as legitimately challenging …........................................157

Bringing intellect to bear .............................................................159

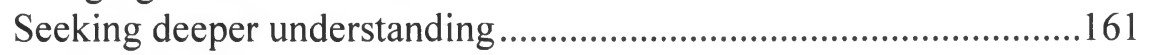

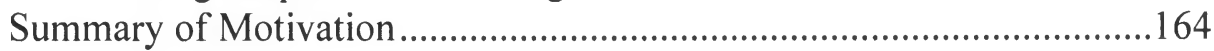

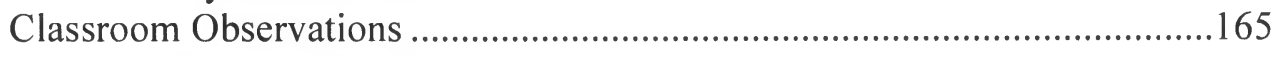

First Classroom Observation...............................................................167

Analysis and summary of first classroom observation .....................180

Second Classroom Observation ............................................................185

Analysis and summary of second classroom observation..................191

Third Classroom Observation ...............................................................194

Analysis and summary of third classroom observation ....................203

Fourth Classroom Observation .............................................................204

Analysis and summary of fourth classroom observation ...................207

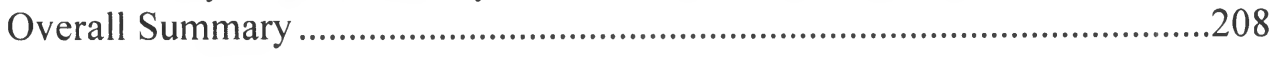

Chapter Seven: Discussion and Recommendations .........................................21

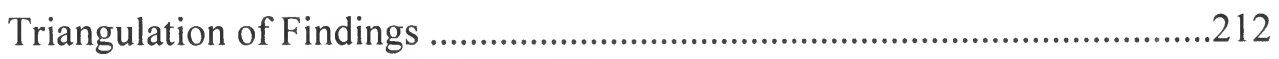

Student Findings by Demographics .....................................................212

Prior Fixed Mindset and Current Growth Mindset ..................................214

Student Motivation to Learn Statistics....................................................219

Limitations of the Study........................................................................22

Implications for Educational Equity ..........................................................222

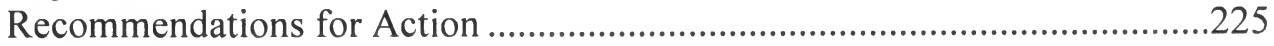

Recommendations for Further Study ......................................................22

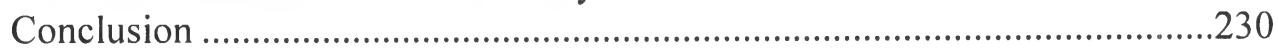

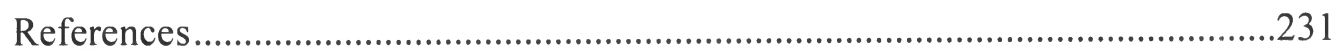

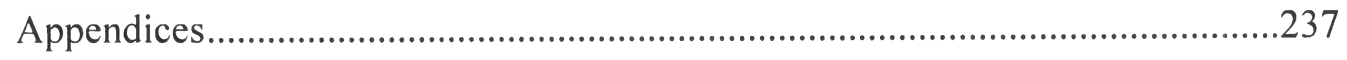




\section{LIST OF TABLES}

Table

Page

1. Final Grade in Pre-Statistics Course by Gender, Age Group, and Puente Status .....87

2. Final Grade in Pre-Statistics Course by Mathematics Course Eligibility.................88

3. Final Grade in Statistics Course by Gender, Age Group, and Puente Status............ 89

4. Final Grade in Statistics Course by Mathematics Course Eligibility ...................... 90

5. Course and Sequence Success by Puente Status ....................................................... 92

6. Hope Scores for StatMode Interviewees and Comparison Groups ........................ 100 


\section{LIST OF FIGURES}

Figure Page

1. Demographic Overview of Interviewees, Ordered by Interview .............................71

2. Percentage of Correct Responses for Questions about Data Exploration and

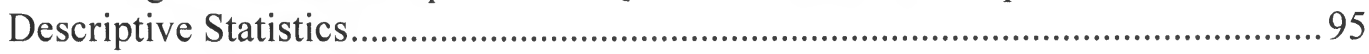

3. Percentage of Correct Responses for Questions about Probability and Inference.... 97 


\section{LIST OF APPENDICES}

Appendix

Page
A. Literature for Developmental Mathematics Sequences
237
B. Interview Protocol Including Hope Scale
240
C. Interview Consent Form............................................................................... 244 
Chapter One: Purpose of the Study

A mixed methods, case study design was used to analyze a community college's implementation of an open-entry, two-course mathematics sequence culminating in transfer-level statistics. The initial pre-statistics course seeks to introduce students to mathematical concepts foundational to learning statistics, thereby preparing students to succeed in the second course which is transfer-level statistics. Enrollment in the sequence includes students placed into the lowest level of mathematics that the college offers (i.e. arithmetic); as such, the sequence attempts to support all students, regardless of initial placement or mathematics eligibility, in reaching college-level statistics by the end of the second semester. Moreover, $97 \%$ of sequence enrollees were underrepresented students of color, a large proportion of whom were first generation college students.

\section{Problem Statement}

Low completion rates for developmental mathematics sequences and in gateway mathematics courses prevent a majority of community college students from achieving their educational goal of transfer. Approximately one-third of students who enter community colleges with developmental mathematics needs advance to college-level mathematics (Bailey, Jeong, \& Cho, 2009; Roksa, Jenkins, Jaggars, Zeidenberg, \& Cho, 2009). Conversely, early completion of college-level mathematics is among the most salient variables contributing to community college student goal achievement and 
transfer (Adelman, 2005; Moore, Shulock, \& Offenstein, 2009). Students who completed college-level mathematics within their first two years at a California community college were three times more likely to transfer or complete a degree or certificate (Moore, Shulock, \& Offenstein, 2009).

To reach college-level math, many students must complete lengthy developmental sequences. The Center for Student Success ([CSS], 2005) indicated that over $70 \%$ of California community college students who took a placement test placed into developmental math, i.e. below advanced algebra or pre-calculus. The National Center for Education Statistics ([NCES], 2003) reported that in the U.S., public twoyear institutions on average offer 3.4 remedial mathematics courses. Sequences of this length can be completed in two years, assuming continuous mathematics enrollment and successful completion of each mathematics course upon first attempt-yet only $17 \%$ of California community college students achieved college-level mathematics within two years (Moore, Shulock, \& Offenstein, 2009). Some students do not even attempt the sequence. In the national study by Bailey, Jeong, and Cho (2009), 27\% of students never enrolled in developmental mathematics after having been referred.

Research shows that African American and Latino students experience even less success than their white and Asian peers in lower-division math. Of those attempting elementary algebra in California community colleges, roughly $40 \%$ of African American and $47 \%$ of Latino students successfully complete the course, compared to 
$53 \%$ of white students and 55\% of Asian / Pacific Islander students (CSS, 2005). These course completion gaps are mirrored by gaps in transfer rates. Moore, Shulock, and Offenstein (2009) reported seven-year transfer rates for Latino and African American students ranging from $16 \%$ to $18 \%$, compared to $27 \%$ for White students and $30 \%$ for Asian students. According to figures from the state's longitudinal database, as of the most recent reporting year (2003-04), transfer rates have marginally improved by one to five percentage points, but achievement gaps in transfer have not changed substantially since 1998-99 (CCCCO Data Mart, n.d.).

Structures associated with lowering student success in mathematics and contributing to achievement gaps precede the community college level. High school mathematics curricula affect students' trajectories. According to national research, lower high school mathematics achievement corresponds to initial community college enrollment while higher achievement was associated with immediate four-year enrollment, as evidenced by a Pearson correlation of $.7525(p=.0001)$ (Adelman, 2005). Studies have shown that underrepresented minority students are less likely to attend high schools which offer advanced mathematics courses (Adelman, 2006; Orfield \& Lee, 2006).

Current discussions about how to improve community college developmental mathematics sequence completion rates emphasize the potential importance of accelerating mathematics sequences through a variety of modifications including short- 
term "refresher" courses, self-paced courses, and shortened sequences (Asera, Navarro, Hern, Klein, \& Snell, 2009a; Bailey, Jeong, \& Cho, 2009; Biswas, 2007; Calcagno, Crosta, Bailey, \& Jenkins, 2006; Wlodkowski, 2003; Wlodkowski \& Kasworm, 2003; Zachry, 2008). In addition to the length of remedial mathematics sequences, there are concerns raised in the field about the effectiveness of approaches used for teaching developmental mathematics as well as the appropriateness of the focus of developmental content. In terms of the latter, researchers point out that very few students (roughly $5 \%-20 \%$ ) who enroll in algebra need or intend to eventually enroll in calculus (Dunbar, 2006; Herriott \& Dunbar, 2009; McGowen, 2006). These researchers suggest that algebra content and course sequences should be examined for relevance and adjusted to fit the needs of students and the disciplines in which they intend to major. Mathematics leaders such as Steen (2004), past president of the Mathematics Association of America, urge colleges to focus on addressing students' quantitative literacy needs, possibly through the use of statistics courses and other courses which focus more on applied use (see also Ganter, 2006; Snell, 2009a).

Advancing complementary arguments, distinguished researchers such as Grubb (2001) assert that an instrumental approach to developmental education hinders student learning. An instrumental approach views the subject matter as a means to some other ends, rather than valuable in its own right. Some believe contextualization, which relates subject matter to authentic, real-world situations, may become a preferred 
approach to teaching developmental concepts more generally, including developmental mathematics (CSS, 2009; Grubb, 2001; Office of Vocational and Adult Education, 2005). Other instructors have sought to further deepen the relevance of mathematics material for students by employing culturally relevant pedagogy (Enyedy \& Mukhopadhyay, 2007).

From a discipline standpoint, mathematics is the most significant barrier to transfer that community college students face (Adelman, 2005; National Center for Education Statistics [NCES], 2003; Moore, Shulock, \& Offenstein, 2009).

Restructuring or reforming mathematics at community colleges so that it does not remain a roadblock would improve transfer numbers overall—and would undoubtedly go a long way toward reducing disparities in the rates at which different ethnic groups transfer. This study focused on a new approach to teaching developmental mathematics utilizing an accelerated sequence and contextualized statistics. Despite the broad interest in acceleration and contextualization, a limited number of published studies have investigated the effectiveness of these approaches. In fact, to date there are no published studies of developmental mathematics sequence acceleration utilizing statistics contextualization at community colleges.

\section{Research Objectives}

\section{Quantitative Hypotheses}

Quantitative hypotheses focused on course completion measures, sequence 
persistence rates, and sequence completion rates, as well as test performance for students in StatMode. (Note, StatMode is a pseudonym.) The primary hypothesis was that a large majority of students in StatMode would be able to complete the initial course successfully and persist to the second, transfer-level course-compared to a minority of similar students nationally. Quantitative analysis of items from the Comprehensive Assessment of Outcomes in a First Statistics Course (CAOS) test was used to examine the hypothesis that StatMode students' performance would be equal to their national peers on the post-test items. Demographic variables including ethnicity, gender, age group, and Puente status — as well as students' mathematics levels upon entering the StatMode sequence-were examined for potential relationship to student success in the sequence. Finally, the Adult Dispositional Hope Scale (ADHS) was used to collect students' self-assessed ratings regarding their individual sense of agency for and pathways to goal attainment. The primary use of the ADHS was to determine whether StatMode students may be atypical with regard to their hopefulness. The hypothesis was that StatMode students were not substantially different than their peers at other colleges regarding their sense of pathways and agency.

\section{Qualitative Propositions}

The qualitative data sought to explore, from the students' perspective, the reasons why StatMode might be effective. Collected primarily through individual student interviews, triangulated with classroom observations and discussions with the 
instructor, the qualitative data examined students' experiences in the pilot mathematics sequence. Data collection focused on the following:

- students' feelings and beliefs about mathematics and the nature of the mathematics concepts they are learning,

- $\quad$ perceived relevance of the content, including contextualization and cultural relevance, and

- shifts in students' sense of competency with regard to learning and using mathematics concepts.

Other aspects of StatMode were also investigated for conscious saliency to the students, including propositions that the following attributes contribute to students' willingness to persist through challenging mathematics material:

- caring relationships between the instructor and the students;

- early, encouraging feedback from the instructor; and

- $\quad$ peer support, particularly that derived from the learning community associated with Puente.

Finally, a potential criticism of StatMode was explored. This criticism reflects the conundrum that StatMode may be viewed as a tracking mechanism or a detracking mechanism, depending on one's perspective. StatMode can be viewed as a detracking effort, bringing developmentally-placed students rapidly into college-level content. Simultaneously, StatMode may track students away from mathematics-intensive and science-related majors. To better understand this issue from the students' perspectives, students' direct and indirect statements about mathematics sequences were analyzed. The related qualitative proposition was that college students would be inclined to view 
StatMode as a detracking mechanism.

\section{Conceptual Framework}

Two primary concepts undergird StatMode. The first concept pertains to removing the structural barriers which currently impede students who place as low as arithmetic from completing college-level mathematics within one year. In order to accomplish the one-year timeframe, it is presumed that challenging, conceptual mathematics content must be incorporated even while remedial mathematics is being reviewed. The second concept pertains to providing a student-centered classroom environment utilizing an instructional approach which consciously facilitates students' sense of agency and competency in math, including incorporating mathematics content which is relevant to students. In addition, mechanisms for peer support are built into the cohort / learning community model leveraged by StatMode.

The length of community college developmental mathematics sequences and the practice of segmenting mathematics material between remedial and college-level (i.e. between rote, rule-bound material and more conceptual, intellectually challenging material) constitute a structural barrier. This barrier contributes to the inequitable achievement of transfer and other completion goals and also deprives many students of the opportunity to engage with rigorous conceptual content in math. The structural argument derives from landmark research by Bowles and Gintis in 1976 which showed that despite increasing education levels across various segments of the U.S. population, 
widespread equality of income and social status had not followed. In their analysis, schools largely legitimate rather than subvert inequities by providing a pretense toward equity and egalitarianism.

Subsequent influential research by Jean Anyon elaborated on the types of learning experiences associated with schools serving different student populations. As reported by Finn (1999), the working class schools which Anyon studied emphasized compliance and following instructions; there could only be one correct approach - the teacher's formulaic approach. In the middle-class school, students were expected to develop conceptual understanding, not just follow rules. However, in the affluent professional school, creativity, discovery, direct experience, and independent work were valued; power and control were negotiated between students and teachers. Finn noted several formal and informal studies in the 1990s which validated Anyon's findings and concluded, "When students begin school in such different systems, the odds are set for them" (p. 25).

Related studies of tracking find that even within institutions students can experience similar differences in teacher expectations of students (Burris, Heubert, \& Levin, 2006; Watanabe, 2008a, 2008b). Watanabe (2008b) found that higher-tracked seventh-grade students received more instructor feedback (both in real time and in written format), practiced a broader range of skills, engaged in more socially situated learning, and considered topics which tended to be both more authentic and more 
challenging. Although tracking purports to place students by perceived ability level, the practice has been criticized for reinforcing inequities relating to ethnicity, class, and other demographic differences. Several detracking efforts in secondary education provide evidence that increased classroom heterogeneity (that is, a mixture of incoming skill levels) can improve student performance across ability levels when coupled with a variety of student-centered instructional approaches (Boaler, 2008; Boaler \& Staples, 2008; Burris, Heubert, \& Levin, 2006).

A second underlying concept of StatMode is that instruction should be relevant and engaging for students. Drawn from pedagogues ranging from Dewey to Freire, hooks, and Ladson-Billings, the concept of relevance reflects a fundamental belief that instructors must attend to the students' experience and relate the educational content to real applications which are meaningful to students. In his theory of experience Dewey (1954) emphasized the importance of being able to apply knowledge. He stated, "There is no such thing as educational value in the abstract" (p. 46). Dewey cited the need for what he referred to as an experiential continuum rather than planless improvisation. In addition, Dewey developed the notion of "interaction" whereby there is a mutual adaptation which takes the learning environment, the students' needs, and social conditions into account. Taken together, these notions are foundational to a constructivist view of education and the promotion of a democratic classroom which emphasizes the "freedom of observation and of judgment exercised in behalf of 
purposes that are intrinsically worthwhile" (p. 69).

Other theorists have built on Dewey's conceptions, arguing for learning environments and relationships with instructors which promote the development of students' independent intellect and agency. For example, Freire argued against "banking" where "the students are the depositories and the teacher is the depositor" (2009, p. 72). According to Freire, this form of instruction promotes passivity. Hooks argued that students "want knowledge that is meaningful...addressing the connection between what they are learning and their overall life experiences” (1994, p. 19).

Relevance can take on many meanings for both instructors and students. In her ground-breaking work, Ladson-Billings (1994) noted that cultural referents may be used pragmatically, simply as "bridges" to encourage student interest or help students understand a particular concept via cultural appropriateness, cultural responsiveness, or cultural compatibility approaches. While potentially effective for teaching students particular skills, Ladson-Billings argued that these approaches fall short. She argued that such cultural referents should be incorporated into culturally relevant teaching which "empowers students intellectually, socially, emotionally, and politically by using cultural referents to impart knowledge, skills, and attitudes" (p. 18).

Current theories of cognition support the importance of a meaning-centered approach to instruction rather than an exclusive focus on memorization and procedures (Bransford, Brown, \& Cocking, 2000). For competence to emerge, facts must cohere 
into a deeper conceptual understanding. Researchers caution not to overlook concerns about students' ability to abstract and transfer knowledge. Retrieval and application of information learned in only one context may be limited to that context. Such knowledge is referred to as "overly contextualized" (p. 62). Use of multiple cases, "what-if" problem solving, and tasks which require generalization or abstraction were shown to increase flexible application and knowledge transfer.

The theoretical framework for this study is informed primarily by pragmatism and social justice concerns. A majority of community college students experience mathematics as a barrier, and this barrier currently serves to reproduce structural inequities which exist in the U.S. Rather than remain entrenched in historical and theoretical notions of the value of mathematics (e.g., mathematics teaches students to think deductively), it seems sensible to consider alternatives. The StatMode alternative would provide students with fundamental skills in mathematics (e.g., quantitative literacy) while allowing that fostering reasoning and other math-associated skills may be accomplished not only through mathematics but also through a variety of disciplines. Moreover statistics can be taught with academic rigor (Moore \& Witmer, 1991). Preconceptions about the rigorousness of one course of study versus another-as well as the necessity of one subject area over another-must be examined closely when the impact is as influential over student outcomes as that of developmental math. 


\section{Key Constructs and Operational Definitions}

Accelerated Program. By definition, these programs take less time to earn credits, certificates, or degrees than traditional programs. Wlodkowski (2003) indicated that the "core element" to an accelerated program is the accelerated course.

College-level Mathematics. Commonly defined as college algebra or a course transferable to a four-year college or university.

Completion Rate. An overarching term that variously refers to transfer rate, graduation rate, course or sequence success rate. The specific reference is defined upon use.

Contextualized Learning. Instruction that relates subject matter to authentic, real-world situations, especially foundation skills which may be linked to academic or vocational content (CSS, 2009). Includes the concepts of "integrated curriculum," "applied learning," and "cognitive apprenticeship." May use learning communities, lab assignments, or other instructional means to link foundational skills with contextual applications.

Course Success. Usually defined as completion of a course with a grade of $\mathrm{C}$ or better, particularly because many colleges will not allow students to take a subsequent course in a mathematics sequence with a "passing" grade of D. Depending on the context of its use, "Success Rate" may refer to "Course Success Rate" or "Sequence Success Rate".

Developmental / Remedial Mathematics. Generally refers to courses below college- 
level math. The numbers of developmental / remedial courses varies among community colleges (NCES, 2003). When possible during the discussion of a particular study, more specific descriptions are used (e.g., basic arithmetic, elementary algebra, intermediate algebra, algebra 2, et cetera). Although the term "remedial" is sometimes considered derogatory, it is used interchangeably with "developmental" in this literature review in order to avoid the overuse of either word (Bailey, Jeong, \& Cho, 2009), as well as to more accurately reflect the varied use in the research studies.

Gateway Course. Usually refers to the initial college-level course in the sequence. Also referred to as "Gatekeeper” (Roska, Jenkins, Jaggars, Zeidenberg, \& Cho, 2009). Quantitative Literacy. This concept appears to be gaining prominence and is subject to completing definitions. One definition is the "uniquely modern blend of arithmetic with complex reasoning" (Steen, 2004, p. 3).

$\underline{\text { Sequence Success. }}$ Completion of all courses in a particular content sequence such as the mathematics sequence or English sequence, including completion of Gateway / Gatekeeper course. Depending on the context of its use, "Success Rate" may refer to "Course Success Rate" or "Sequence Success Rate."

Tracking. An approach to instruction that sorts students by perceived ability level. "At the secondary level, tracking manifests itself in the form of honors, regular, or remedial classes by subject" (Watanabe, 2008, p. 672). Historically, two primary characteristics of tracking include lesser content provided to and lower levels of critical thinking 
required of students in lower tracks. Thus, the longer a student remains in one track, the more difficult it is for that student to successfully move up to a higher-level track.

\section{Delimitations and Scope of the Study}

StatMode was selected for this case study because it is atypical. As Bogdan and Biklen (2007) caution, such selection limits the generalizability of the findings. A rich description of the research setting, including detailed descriptions of the study population, the instructor, the nature of the instruction, and the classroom climate, will allow readers to assess potential transferability of the findings.

A mixed-methods approach was employed due to the pilot nature of this curricular intervention. This design, drawn from a pragmatic research framework, focused on the urgent need to improve mathematics sequences for community college students. While there was not a sufficient sample size within the pilot for a full-scale quantitative study, the quantitative data were necessary to justify the importance of the qualitative findings. Qualitative data were vital to investigate the qualities within the StatMode sequence and instructional design which supported students' success and achievement. Due to the unique context and to counterbalance subjectivity, a variety of both quantitative and qualitative data were gathered for corroboration and triangulation in order to present the most complete picture possible of this particular case.

\section{Significance of the Study}

As described in the general overview, early completion of college-level 
mathematics acts as a catalyst to transfer for community college students, just as lack of mathematics completion acts as a barrier. The mathematics hurdle, as it is often called, impacts the number of community college students who become degree- or transfereligible. This is problematic for the students who seek to achieve their goals. It is also problematic for community colleges which may be increasingly funded based upon efficacy — either directly through performance-based funding or indirectly based upon legislators' perceptions of the colleges' effectiveness. Finally, the hindrance to degree production affects the social and economic health of individual states as well as the U.S. as a whole (Moore, Shulock, \& Offenstein, 2009).

No other discipline has such a powerful effect on student outcomes. Yet there are no widely-implemented or widely-accepted remedies which ameliorate the mathematics hurdle. As will be discussed in the literature review, commonly-used interventions such as tutoring, Supplemental Instruction, and computerized software have not been found to both regularly and definitively improve student success rates in developmental math. More intensive mathematics interventions may be successful but are not considered scalable; they are resource-intensive for both colleges and students. Intensive programs such as MathPath (MathPath, n.d.) boast course success rates as high as $80 \%$ in beginning algebra, compared to success rates of $40 \%$ for students not in the program. However, enrollment in the program requires that students spend 30 hours a week on math -10 hours in class time and 20 hours outside of class. 
StatMode represents a new approach to restructuring the developmental mathematics sequence and content. Growing national interest in the primary components of StatMode is reflected in the acceleration and contextualization themes cited in the literature review. Despite the broad interest in acceleration and contextualization, only a limited number of published studies have investigated the effectiveness of these approaches. There are no published studies of developmental mathematics sequence acceleration utilizing statistics contextualization at community colleges.

This study of StatMode seeks to show the potential viability of an accelerated, contextualized model in terms of student outcomes. It also seeks to reveal student experiences within StatMode. The demographics of StatMode students reflect some of the most underserved students in the educational system: roughly $80 \%$ of StatMode students are Latino and $70 \%$ are first generation college-going. In addition, $20 \%$ or more of StatMode students have completed only arithmetic or elementary algebra in high school, with an even higher proportion placing at or below elementary algebra upon community college matriculation. In part, the design of the research questions and the research protocol attempt to consciously leverage these demographics in order to focus findings on equity issues.

\section{Conclusion}

Low completion rates for developmental mathematics sequences and in gateway 
mathematics courses prevent a majority of community college students from achieving their educational goal of transfer. Moreover, research shows that African American and Latino students experience even less success than their white and Asian peers in lowerdivision math. In national debates regarding how to redress these issues, two frequently proposed modifications include shortened, accelerated sequences and contextualization. To date there are no published studies of developmental mathematics sequence acceleration utilizing statistics contextualization at community colleges.

Through an explanatory mixed methods approach, this study analyzed success rates of all 29 StatMode enrollees, including testing for statistical significance across several demographic variables. The study then used a close analysis of 11 student interviews - triangulated with four classroom observations and discussions with the instructor-to explain the success rates from the students' perspectives.

Organization of the Dissertation

The next chapter presents a review of the literature that guided this investigation. The third chapter presents the study methodology. Chapter Four focuses on the results of the quantitative analysis. Chapters Five and Six present the qualitative findings. The final chapter addresses the significance of and implications of the results, as well as suggestions for future research. 


\section{Chapter Two: Literature Review}

\section{Introduction}

Low completion rates for developmental mathematics sequences and in gateway mathematics courses prevent a majority of community college students from achieving their educational goal of transfer. Most community college students begin their postsecondary education with a disadvantage in mathematics. A landmark national study showed that mathematics achievement in high school is strongly associated with the type of institution where initial postsecondary matriculation occurs. Lower high school mathematics achievement corresponded to initial community college enrollment while higher achievement was associated with immediate four-year enrollment, as evidenced by a Pearson correlation of $.7525(p=.0001)$ (Adelman, 2005). For the 1992 cohort of $12^{\text {th }}$-graders, $43.5 \%$ of students entering community colleges had not reached the level of algebra 2 in high school. In comparison, $11.4 \%$ of students entering fouryear institutions had not reached algebra 2 . Conversely, only $7.6 \%$ of community college entrants had reached pre-calculus or calculus in high school, compared to $40.0 \%$ of four-year matriculants.

Not only do a majority of community college students place low, but many students never make it beyond their first mathematics course. According to the Center for Student Success (2005), more than $50 \%$ of students attempting elementary algebra fail to achieve a passing grade of $\mathrm{C}$ or higher in California community colleges. In a simple demographic analysis, success rates were found to vary by ethnic group. 
Roughly $60 \%$ of African American community college students in California fail elementary algebra, compared to $53 \%$ of Latino students, $47 \%$ of white students, and $45 \%$ of Asian / Pacific Islander students. Underrepresented students are more likely to place at the lowest level, a fact compounded by success rates which are also lower. Yet before attempting to fulfill college-level mathematics requirements, students must successfully complete not only elementary algebra but also intermediate algebra since the latter is a prerequisite for fulfilling quantitative reasoning transfer requirements.

Low placement and success rates in mathematics courses are a well known problem, but more recent studies have focused on the large proportion of students who never attempt mathematics after receiving a developmental placement, or who fail to complete the mathematics sequence even after having successfully completed all the mathematics coursework they attempted. Bailey, Jeong, and Cho (2009) in their study of Achieving the Dream schools found that $27 \%$ of students never enrolled in developmental mathematics after having been referred and $11 \%$ never failed a mathematics course yet did not complete the sequence. Taken together, this $38 \%$ is substantially higher than the $29 \%$ who failed at least one mathematics course and did not complete the sequence. It is also higher than the $33 \%$ of students who successfully completed the developmental sequence and reached transfer level.

Numerous studies and reports have suggested that community colleges currently do not transfer students in sufficient numbers-making both California and the nation less competitive globally as a result (Callan, Finney, Kirst, Usdan, \& Venezia, 2006; 
Shulock \& Moore, 2007). From a discipline standpoint, mathematics is the most significant barrier to transfer that community college students face (Adelman, 2005; National Center for Education Statistics [NCES], 2003; Moore, Shulock, \& Offenstein, 2009). Student transfer rates will improve only when student success in mathematics improves and/or mathematics requirements are changed. Restructuring or reforming mathematics at community colleges so that it does not remain a roadblock would improve transfer numbers overall--and would undoubtedly go a long way toward reducing disparities in the rates at which different ethnic groups transfer.

Further amplifying the importance of mathematics specifically is the increased need for greater mathematical skills among workers--skills remarkably consistent with those required for postsecondary education (Office of Vocational and Adult Education, 2005). Due to these pressures, mathematics requirements in states such as California, for example, have been increasing at both the K-12 and community college levels. Various interventions have, in some cases, improved mathematics success rates but only marginally. As a result, there is the potential for further widening current achievement gaps between ethnic groups if mathematics success rates are not substantially addressed. Simultaneously, among national, professional mathematics associations such as the American Mathematical Association of Two-Year Colleges (AMATYC), the Mathematical Association of America (MAA), and the National Council of Teachers of Mathematics (NCTM), there is a general agreement that the developmental mathematics curriculum needs to be revised to improve student success rates. 
Specifically, mathematics associations recognize that a majority of college students, including community college students, do not require calculus to fulfill their major requirements-yet traditional mathematics pathways emphasize preparation for calculus over other mathematical skills (Hastings, 2006). Alternative mathematics pathways at community colleges are being investigated to determine whether they can simultaneously maintain a sufficient level of rigor, dramatically increase student success levels in math, decrease achievement gaps in math, and provide meaningful skills for a broad range of community college students. Possible pathways include an approach to teaching developmental mathematics and algebra concepts and procedures required as preparation for a college-level statistics course, rather than calculus.

Clearly these approaches (acceleration and contextualization) exist among many options for improving mathematics performance and sequence completion, particularly for underrepresented students. Given the growing interest in cultural relevance at community colleges, literature will be included to the extent that it specifically addresses cultural relevance used in teaching statistics material through a social justice lens. Cultural relevance may, depending on the approach, deepen the degree of relevant contextualization, but it may also divert students from statistics learning goals.

Finally, as a partially inductive, explanatory mixed methods study, the research remained open to the possibility that other frameworks and concepts would become important. As a result, a major framework which emerged during qualitative data collection has been incorporated into this literature review. The framework compares 
the implications of entity versus incremental theories of intelligence (TOIs) for learning. Popularized in the nonacademic literature as "fixed mindset" and "growth mindset," these TOIs have been shown to be associated with performance when students engage with challenging material. The framework has also been used to address stereotype threat experienced by members of marginalized populations.

\section{Scope and Search Criteria}

An initial ProQuest search of Education Journals for (math* AND community college" AND statistics) yielded no empirical studies. Broadening the search to (math* AND college AND statistics) yielded more results; however, upon review the studies were nearly all university-based and seemed far removed from the community college experience. The search for "statistics pathway" references yielded no studies. Finally, results for subsequent, topical searches were also scant, including (math* AND "community college" AND (heterogeneity OR tracking OR ability-grouping)), which yielded one study.

Thus, the scope of the literature review was substantially broadened to investigate what is known about developmental mathematics instruction and course sequences at community colleges. A broad, initial search conducted using ProQuest, selecting for Scholarly journals across all databases, revealed a total of only 66 articles, of which 57 were published during the decade from January 2000 through December 2009. The search syntax used was as follows: (math*) AND (community college OR two-year college) AND TEXT(remedia* OR developmental OR basic skills). Adding 
"OR algebra" and "OR junior college" to the search text did not reveal additional articles.

The 57 most recent articles were examined for empiricism and relevance. Opinion pieces were excluded. Others articles which did not focus on community college students were excluded - for example, articles focused on high school students concurrently enrolled at a community college. Several articles on assessment and placement were set aside in order to focus on student success in mathematics sequences, promising instructional interventions, and potential structural changes. Ultimately, 13 articles were identified for potential inclusion in the literature review. A similar search in EBSCO only added three more articles. These studies focus on success rates in mathematics sequences, the use of technology in mathematics courses, tutoring and supplemental instruction, and contextual learning.

Several education and mathematics experts were consulted regarding how to supplement the ProQuest and EBSCO articles. As a result, substantial articles were added from the following sources: The Community College Research Center (CCRC) and Achieving the Dream. Extensive branching was also used to locate relevant studies.

To further ground the researcher's sense of the developmental mathematics field, articles and conference proceedings from the preeminent mathematics organizations mined, in particular the MAA and AMATYC. For example, $35^{\text {th }}$ AMATYC Annual Conference was held November 12-15, 2009, in Las Vegas. For the 
latter, out of 149 individual sessions, 15 clearly focused specifically on developmental mathematics based upon their titles. Other foci ranged from the use of technology, statistics instruction, quantitative literacy, calculus, and approaches to professional learning.

Finally, as noted in the overview, two concepts were added during the course of this explanatory study based on preliminary findings. Additional concepts include theories of intelligence (i.e. incrementalist and entity TOIs associated with popularized notions of growth and fixed mindsets) and cultural relevance insofar as it is related to statistics instruction.

Structure of the Review

The literature review begins with a discussion of the particular role mathematics plays in students' trajectories. The landmark research study Moving Into Town-And Moving On by Clifford Adelman (2005), former Senior Research Analyst for the U.S. Department of Education, is probably the most extensive quantitative study of community colleges to date. At 175 pages, the study provides a complex view of community colleges using a larger array of variables than is available to most other researchers in the field. Due the comprehensiveness and complexity of the analysis provided by Adelman, the literature review devotes substantial attention to this study.

A synthesis of studies examining the effectiveness of developmental education follows the section on the particular role of mathematics in student trajectories and academic momentum. The relative effectiveness for diverse populations is also 
examined, followed by a discussion of the approaches used by community colleges to attempt to improve the effectiveness of developmental mathematics courses and sequences.

Finally, the additional concepts of entity and incrementalist TOIs and statistics instruction taught through a cultural relevance framework are all addressed.

\section{Analysis of the Research Literature}

\section{Mathematics as Catalyst or Barrier}

Early completion of college-level mathematics acts as a catalyst to transfer for community college students, just as lack of mathematics completion acts as a barrier. Adelman (2005) found that nationally, the completion of college-level mathematics during a student's first year at a community college was among five variables significantly associated with the likelihood of transferring to a four year institution. With each increase in mathematics level, the probability of transfer increased by $22.7 \%$.

In their study of California community colleges, Moore, Shulock, and Offenstein (2009) found similar results: completion of college-level mathematics within the first two years of enrollment resulted in a three-fold increase of overall completion rates (i.e. transfer, certificate, or degree). College-level English within the first two years of enrollment was associated with a two-fold increase in overall completion rates. In their regression model, both completion of college-level mathematics and collegelevel English within the first year were significant. The difference from Adelman's findings in terms of English may be related to the relatively large proportion of non- 
native English speakers in California.

Beyond mathematics and English, other variables associated with transfer included earning credits during a summer term, continuous enrollment and, negatively associated, the accumulation of withdrawal and repeats (Adelman, 2005). The final variable associated with transfer was "attendance in more than one state"-an unexpected finding Adelman suggested warrants further investigation. Like Adelman, Moore, Shulock, and Offenstein (2009) found that summer credits, continuous enrollment, and a low proportion of course withdrawals or course failures were positively associated with completion. In addition, they found that the number of credits earned during the first year also showed a positive, linear relationship with completion. Late course registrations, conversely, were negatively associated with completion rates.

Variables not directly associated with transfer included SES, ethnicity, and other student demographics (Adelman, 2005). However, the group of students Adelman identified as most likely to transfer and earn a Bachelor's degree was also disproportionately white, among the highest SES quintiles, and less likely to be firstgeneration postsecondary. Characteristics of the most successful group were as follows: they successfully completed 30 or more units, but less than $60 \%$ of those units were completed at community colleges, $77 \%$ earned a bachelor's degree, $43 \%$ completed college-level mathematics in their first year, and $84 \%$ were white. By contrast of students who earned fewer than 30 units at community colleges, just $5 \%$ earned a 
bachelor's degree, $7 \%$ had completed college-level mathematics in their first year, and $66 \%$ were white. To provide a fuller demographic picture, of the group of students more likely to transfer, 4\% were African American, 7\% Latino, and 5\% were Asian; $29 \%$ were in the highest SES quintile; and $16 \%$ were first-generation postsecondary. Of the less successful group, 12\% were African American, 24\% Latino, and 5\% Asian; $12 \%$ were in the highest SES quintile; and $31 \%$ were first-generation.

In a subsequent report, Adelman (2006) investigated the trajectories of all traditional-aged postsecondary students who attended a four-year institution at any time, thus may or may not have started their postsecondary studies at a community college. In this study he again makes the case that high school "curriculum counts," especially for African American and Latino students. "Differential lack of opportunity-to-learn was a major theme in the original Tool Box and is just as prominent a theme in this study of a cohort a decade later (p. 31)." African American and Latino students were less likely than white students to attend high schools which offered calculus, for example; the respective percentages were $51 \%, 45 \%$, and $59 \%$.

Adelman's reports $(2005,2006)$ focused on traditional-aged students using the National Education Longitudinal Study of 1988, which followed 25,000 U.S. eighthgraders through high school and was supplemented by postsecondary transcripts, as his primary data source. This represents a significant portion of the postsecondary student body, but certainly not all. Adelman (2005) reported that $58 \%$ of credit-enrolled community college students in 2001 were under 24 years old. In contrast, the study by 
Moore, Shulock, and Offenstein (2009) included community college students of all ages. Again, these studies highlighted the importance of mathematics in the trajectories of community college students.

As a discipline, mathematics acts as a uniquely problematic gatekeeper in other ways as well. Skills in English, reading, and composition are critical to students' success in college. Underdeveloped skills in these English, reading, and composition contribute to students' lack of success in a range of college-level courses, for example psychology (Goldstein \& Perin, 2008; Spurling, 2007). In comparison, many students placed into developmental mathematics either are not interested in math-intensive fields or are discouraged by their placement from pursuing math-intensive fields. They may not require mathematics skills for the majority of their coursework. These students may perform well in other academic areas, but the difficulty in completing college-level mathematics requirements can-by itself-obstruct transfer.

The Climb to College-Level Math

While completing college-level mathematics in the first year might be highly advantageous for a transfer-trajectory, many students entering community colleges cannot currently hope to achieve this feat. Approximately $44 \%$ of traditional-aged community college students left high school having completed a mathematics class prior to Algebra 2 (Adelman, 2005). Similarly, a survey of California community colleges showed that $47 \%$ of students entered at two or more levels below college-level mathematics (Center for Student Success [CSS], 2005). NCES (2003) reported that in 
the U.S., public two-year institutions on average offer 3.4 remedial mathematics courses.

Approximately one-third of students who enter community colleges with developmental mathematics needs advance to college-level mathematics (Bailey, Jeong, \& Cho, 2009; Roksa, Jenkins, Jaggars, Zeidenberg, \& Cho, 2009). For this one-third, mathematics remediation can be described as successful: students who complete remedial sequences tend to complete college-level coursework and persist to degree completion. In two statewide studies, researchers found that students who complete developmental mathematics sequences subsequently complete college-level mathematics coursework at rates similar to their more prepared peers who place directly into college-level mathematics upon matriculation (Bahr, 2008; Roksa, Jenkins, Jaggars, Zeidenberg, \& Cho, 2009). Bahr's study examined the entire California community college system, while Roksa, Jenkins, Jaggars, Zeidenberg, and Cho investigated community colleges throughout Virginia. It might be considered encouraging that some developmental mathematics students- those who were successful-were able to reach parity with students who entered placing higher in math. However, in addition to the low proportion of students to whom this applied (one-third), neither study investigated ethnicity or other demographic variables to determine whether this success was experienced equally across various groups. Instead, the studies controlled for ethnicity and other demographic variables.

In a smaller-scale study, students who completed elementary algebra scored less 
than one-half point lower on the assessment test than students placing directly into intermediate algebra (Parmer \& Cutler, 2007). Although smaller in scope, the study shows how detailed analysis can isolate particular areas for colleges to focus on, which in this case were absolute value, simplification, solving linear equations, involving fractions, and calculating percents. In these specific areas, elementary algebra completers scored ten percentage points lower. The study also shows how local perceptions may differ from statewide or national views due to temporal or institutional variation. The study was comprised of modest-sized samples (the $n$ varied for each aspect of the study, ranging from 641 to 1,028 ) and was not longitudinal (only one instructional quarter was investigated).

Three other state-wide studies took a different approach to assessing the effectiveness of remediation by examining students at the margins of remedial placement--and found conflicting results. By examining similar students per ACT and SAT scores with different placements per local college policy, Bettinger and Long (2009) found public postsecondary students in Ohio who took remedial courses achieved better retention and degree completion rates. Specifically, they found that students placed into developmental mathematics were $15 \%$ more likely to transfer. Similar studies using quasi-experimental regression discontinuity analyses in Florida and Texas did not replicate the findings of the Ohio study. Martorell and McFarlin's unpublished study of the Texas system (as cited in Bailey, Jeong, \& Cho, 2009; Calcagno \& Long, 2008) concluded that students were neither helped nor harmed by 
remediation. Calcagno and Long (2008) found that remediation might promote early persistence, but only slightly. Furthermore, remediation was not associated with improved degree completion rates or improved transfer rates.

Looking at students "at the margins" of placement constitutes both a strength and a limitation of these three studies. The study designs approach a level of causality which is rare in educational research. However, the majority of students with developmental placements are not contained within the analyses, given that in all three cases only "marginal" students were included. Affects of remediation on students placing further down the developmental sequences cannot be assumed to be similar. Some other limitations are worth noting, particularly with the Ohio study since it found the most positive results. The Ohio study focused on full-time, traditional-aged students, raising additional questions of generalizability. Moreover, as with the other state-wide studies, ethnicity and other demographic variables are used as controls rather than explored for potential direct or indirect effects.

The most recent sequence studies have focused on the large proportion of students who never attempt mathematics after receiving a developmental placement, or who fail to complete the mathematics sequence even after having successfully completed all the mathematics coursework they attempted. Bailey, Jeong, and Cho (2009) in their study of Achieving the Dream schools found that $27 \%$ of students never enrolled in developmental mathematics after having been referred and $11 \%$ never failed a mathematics course yet did not complete the sequence. Taken together, this $38 \%$ is 
substantially higher than the $29 \%$ who failed at least one mathematics course and did not complete the sequence. It is also higher than the $33 \%$ of students who successfully completed the developmental sequence and reached transfer level. See also Roksa, Jenkins, Jaggars, Zeidenberg, and Cho (2009).

To summarize, many students who enter community colleges cannot complete the required developmental mathematics courses within the first year, a feat which is characteristic of the most successful community college students. Students who complete developmental mathematics sequences appear to do well in gateway courses. However, only one-third of students placed into developmental mathematics complete the sequence. Many students assessed into remedial levels never enroll in math, and a sizable percentage of students fail to complete the sequence despite being successful in all the mathematics courses they attempt.

\section{Studies of Special Populations and Developmental Mathematics}

Several of the foregoing studies selected for traditional-aged students (Adelman, 2005, 2006; Bettinger \& Long, 2009) or otherwise controlled for age (Bahr, 2008; Calcagno \& Long, 2008; Roksa, Jenkins, Jaggars, Zeidenberg, \& Cho, 2009). Adelman cautioned that age is a critical variable for community colleges and should either be controlled for or investigated. To dramatize his point, he described traditional-age students and older students as coming "from different planets" (2005, p. 12). Partially in response to Adelman, a study of the Florida community college system investigated student success in terms of degree or certification completion by age (Calcagno, Crosta, 
Bailey, \& Jenkins, 2007). They noted that lower completion rates of adults, defined as students between the ages of 25 and 64, have "been accepted as more or less conventional wisdom" but not explained (p. 218). Taking a simple view, Calcagno, Crosta, Bailey, and Jenkins found that $30 \%$ of younger students, compared to $19 \%$ of older students, achieve a degree or certificate within 17 terms. Using hazard models, however, older students were shown to be more likely to complete a degree (1.24 times as likely) after controlling for mathematics placement. Mathematics placement scores for older students averaged 328 compared to 415 for younger students on a scale of 200 to 800 .

Investigation of the impact of community college remediation on Latino students is particularly important for two reasons: Latinos are increasing as a proportion of the U.S. population and, along with American Indian $12^{\text {th }}$ graders, Latinos are much more likely to enroll at a community college. Nationally, roughly $55 \%$ of Latino students and $58 \%$ of American Indian students begin their postsecondary experience at a community college, compared to roughly $38 \%$ for white students, $39 \%$ African American students, and 37\% Asian students (Adelman, 2005). Perhaps counter to common assumptions, these enrollment proportions by ethnic group have remained highly stable between 1972, 1982, and 1992.

A recent study focused on the factors affecting Latino students' community college success, defined as persistence, degree completion or transfer. Using the national Beginning Postsecondary Students dataset, Crisp and Nora (2010) found results 
similar to those of Calcagno and Long (2008): remediation was associated with nearterm persistence. As with Adelman (2005), their analysis also showed a significant association between high school mathematics level and success in years two and three. Conversely, high school GPA was not associated with student success.

Given the importance of equity issues to the field and the limited number of published research articles empirically addressing equity in developmental sequences at community colleges, a few small studies warrant mention despite marked methodological shortcomings. These studies are characterized by small, locallysituated convenience samples and a relatively limited array of variables, both independent and dependent. Dozier (2001), for example, compared the academic records of documented and undocumented international students enrolled at an urban community college in New York during spring 1999 ( $n=294$ and 246, respectively) and found that more undocumented students were identified as requiring developmental mathematics (64\%), compared to documented students (39\%). A two-semester study of intermediate algebra enrollees $(n=1,318)$ at a Texas community college (Fike \& Fike, 2007) found statistically significant differences in end of course grades, $F(2,930)=$ $4.929, p=.007$. White students who comprised $66 \%$ of the sample had higher ending grades $(M=2.20, S D=1.423)$ when compared to Latino students who comprised $25 \%$ of the sample $(M=1.90, S D=1.504)$. Gender and faculty education level (graduate degree or no graduate degree) were also found to be significant, but the full-time or part-time status of the faculty member was not significant. 
Overall, the community college literature on equity issues within developmental mathematics is limited. Some studies have identified differences in success measures by age, gender, or ethnicity. These studies are generally simplistic and do not include socio-economic and academic history variables.

Improving Mathematics Success Rates in Community Colleges

Use of technology.

The use of electronic interventions and approaches is a theme in the literature. Ancillary technological interventions are arguably more readily brought to scale than interventions which fundamentally change instructional practices. One study documented lower success rates of beginning algebra students enrolled in hybrid and distance learning sections of the course, compared to lecture sections (Zavarella \& Ignash, 2009). Students were less likely to withdraw from the lecture sections: $20 \%$ withdrew from lecture courses versus $42 \%$ for hybrid and $33 \%$ for distance learning.

LaManque (2009) investigated the impact of computerized software. LaManque's sample was not randomized, but he makes the case that student selfselection probably was not a factor since students were unaware of the intervention prior to enrolling. Success rates in sections where the computerized software was used were significantly higher $-71 \%-75 \%$ for EnableMathematics sections compared to $55 \%-58 \%$ for the control sections (using Chi-Square, level of significance not reported). While potentially promising, LaManque reports local skepticism regarding these findings. Instructors were not randomly chosen; moreover, instructors were required to 
revise their lesson plans to accommodate the software. Also, in some cases success in subsequent courses was lower for the students who used the computerized software, drawing into further question the legitimacy of the higher initial success rates. One hypothesis was that the software allowed more "marginal" students to succeed in the initial course but the effects did not promote sustained success in subsequent coursework.

The use of technology as a form of delivering instruction or structuring in-class homework sessions can be distinguished from the inclusion of technological tools used specifically within math-related fields. The use of graphing calculators, for example, figures prominently in the MAA and AMATYC discussions. A study of one community college using graphing calculators in beginning algebra suggested that course success rates could be improved substantially (Martin, 2008). During each of the two semesters in which the calculators were used, students earning a B or better increased by ten percentage points. Grades of $\mathrm{C}$ or better increased between five and 12 percentage points.

Despite the interest in technology as evidenced by the 2009 AMATYC conference proceedings where 30 out of 147 sessions focused on some form of technology — by far the most popular theme - the robustness of the community college literature is again limited. Therefore, to augment the findings discussed above, a report is included which was prepared for the U.S. Department of Education. The Office of Vocational and Adult Education (2005) report summarized 15 studies investigating 
efforts to improve outcomes for developmental mathematics, of which nine focused on technological interventions. These studies were drawn from four-year and military settings, as well as conference proceedings; the latter included community colleges. The researchers concluded that the use of technology, relative to traditional instructional formats, "resulted in higher, lower, or no difference in pass rate, no difference or higher rates of persistence to higher-level math, and no difference in final grades" (p. 33). The largest improvement identified appears to have been a $12 \%$ improvement in successful grades in elementary algebra due to the supplemental use of technology via ComputerAssisted Instruction (CAI).

\section{Supplemental instruction and tutoring.}

Two popular interventions used by community colleges in efforts to improve success rates in developmental courses are peer tutoring and supplemental instruction (SI). SI is defined as "a form of peer learning which targets high-risk courses" rather than at-risk students (Phelps and Evans, 2006, p. 22; Zaritsky \& Toce, 2006). Despite widespread use, according to ProQuest searches, only one published study to date has focused on SI for developmental mathematics at a community college, and one study on tutoring more generally. Phelps and Evans used an experimental design at Valencia, a community college in Florida to examine the effects of SI. Results were mixed. Found through EBSCO, Zaritsky and Toce (2006) also investigated SI for "high risk courses" at a community college. Targeted courses were not disaggregated, so the effect of SI on mathematics specifically is unknown, but the researchers reported an average increase 
in 1.24 letter grades over several semesters (spring 1993 through spring 2005). Longerterm affects were not investigated.

Although typically less structured than SI, tutoring also uses a peer learning approach. In their overview of "30 years of research" about remediation, Boylan and Saxon (1999) noted that the impact of tutoring for students in developmental courses has been widely debated. They suggest that the impact of tutoring depends primarily upon having a well-trained tutor. The study identified via ProQuest which focused on math-related tutoring at a community college found that tutoring increased GPA for students who placed into remedial mathematics by .38 points on average after controlling for ethnicity, gender, and course placement (Kostecki \& Bers, 2008). Flaws in this study, however, include the fact that the study did not control for whether the student actually enrolled in a developmental mathematics class; moreover, as the researchers explained, at the community college where the study was conducted, grades were not given for developmental mathematics classes. Thus, it is unknown for which courses GPA increased.

For the SI studies as well as the tutoring study, student motivation was not controlled for, which leaves any positive findings open to an important counterhypothesis: students who are more motivated may simply tend to perform better regardless of tutoring or SI. Perhaps in part because interventions such as tutoring, SI, and computerized software have not been found to both regularly and definitively improve student success rates in developmental math, several researchers have turned to 
structural considerations. These approaches will be discussed next.

Structural changes to the sequence.

Researchers point out that very few students (roughly $5 \%-20 \%$ ) who enroll in algebra need or intend to eventually enroll in calculus (Dunbar, 2006; Herriott \& Dunbar, 2009; McGowen, 2006). These researchers suggest that algebra-related content and course sequences should be examined for relevance, and then the content should be adjusted to fit the needs of students and the disciplines in which they intend to major. Thereby, educators hope to promote greater student success in math.

One approach to structural change is "acceleration." The term "acceleration" is borrowed from the K-12 (Bailey, Jeong, \& Cho, 2009) and can be juxtaposed with community college notions of "intensification" (Asera, Navarro, Hern, Klein, \& Snell, 2009). Intensification entails additional time on task during a prescribed timeframe. Intensification can be accomplished in a variety of ways including through paired coursework (as in learning communities or paired workshop courses), optional or required tutoring sessions (as in SI), or the use of technology. In terms of technology, for example, one rationale for the program LaManque studied was that the software would "assist" students with their homework; some faculty felt students were not spending enough time working on mathematics problems on their own. Intensification can be effective for some students, but it often requires substantial additional institutional resources and by definition requires more students' time.

As with intensification, acceleration takes various forms. Biswas (2007) 
described several approaches being used by community colleges participating in the Achieving the Dream initiative, including mathematics classes which are modular and self-paced so students need to repeat only the portion which they had failed. Although the ProQuest search found no empirical studies of self-paced instruction for developmental mathematics at community colleges, Ironsmith, Marva, Harju, and Eppler (2003) examined self-paced instruction for remedial mathematics compared to lecture mathematics at a large university $(n=272)$. They found no significant mean main effect by class format for final course grade. Rather, they found that goal orientation (learning goal versus performance goal) was significantly associated with performance. The Office of Vocational and Adult Education (2005) report also cited several studies with the same finding: no difference in outcome by course format. None of these self-paced approaches were described as modular.

The effectiveness of self-paced instruction for mathematics may depend on the type of students enrolled. According to some researchers, accelerated approaches may be particularly appropriate for adults who need mathematics remediation (Calcagno, Crosta, Bailey, \& Jenkins, 2007; Wlodkowski \& Kasworm, 2003). Wlodkowski (2003) identified acceleration as a growing area of interest and indicated that $25 \%$ or more of adult, postsecondary students were projected to be enrolled in accelerated programs within ten years. However, Wlodkowski and Kasworm (2003) warned that there may be less "margin for error" in accelerated programs.

Another form of accelerated mathematics which Biswas described is a short, 
"refresher" course provided to students near a cut score on the placement exam. The success of these particular implementations has not yet been determined — only very preliminary data was available for some of the colleges. In an updated report, Zachry (2008) indicated preliminary, promising results for a "Fast Track Math" program utilizing a refresher approach. The sample receiving the intervention, however, was extremely small $(n=10)$.

A third approach to acceleration is to structurally change the course sequence rather than accelerate particular courses (Asera, Navarro, Hern, Klein, \& Snell, 2009). Mathematics leaders such as Steen (2004), past president of the Mathematics Association of America, agree and urge colleges to focus on addressing students' quantitative literacy needs, possibly through the use of statistics courses and other courses which focus more on contextual learning and applied use (see also Ganter, 2006). Initial results from an accelerated, statistics-oriented sequence suggested a shortened approach may be possible, at least for some students (Snell, 2009).

\section{Contextual learning approaches.}

Approaches such as the aforementioned statistics-oriented sequence beg the question of contextualization. Contextualized instruction relates subject content-in this case mathematics content-to authentic, real-world situations (CSS, 2009). Contextualized learning is a growing area of interest at community colleges (CSS, 2009; Grubb, 2001; Office of Vocational and Adult Education, 2005). The CSS report identified the following learning theories as closely related to contextualization: 
motivation theory, problem-centered learning, social learning, and learning styles.

Current theories of cognition support the importance of a meaning-centered approach to instruction rather than an exclusive focus on memorization and procedures (Bransford, Brown, \& Cocking, 2000). Factual knowledge is important, but for competence to emerge these facts must cohere into a deeper conceptual understanding. By definition contextual learning is meaning-centered; however, researchers caution not to overlook concerns about students' ability to abstract and transfer knowledge. Retrieval and application of information learned in only one context may be limited to that context. Such knowledge is referred to as "overly contextualized" (p. 62). Use of multiple cases, "what-if" problem solving, and tasks which require generalization or abstraction were shown to increase flexible application and knowledge transfer. Metacognition, as emphasized in active learning environments, also has been shown to improve transfer.

Over time, contextual approaches, formerly referred to as "applied learning," became associated with low expectations (Bond, 2004). Applied learning can be taught in didactic, discrete skills-focused ways which are not learner-centered or engaging (Grubb, 2001). The current resurgence of interest in contextualization seeks to counter these negative associations by using learner-centered approaches and by coupling applied learning with deep conceptual and academic understanding (Bond, 2004; CSS, 2009). Thus, the preferred terms contextualization and cognitive apprenticeship reflect more current conceptions of teaching foundational content through applied relevance. 
The pointed emphasis on contextualization may not be as prevalent in $\mathrm{K}-12$ systems as in community colleges. Students enrolled in community colleges often major in a discipline, arguably making practical applications within that field a natural focus of students' interest, as well as a site of meaning. Moreover, the emphasis on contextualization within community college instruction is codified into law. The Carl D. Perkins Career and Technical Education Act (Perkins Act) requires that community colleges integrate academic and vocational education for improved student performance and outcomes (CSS, 2009). This emphasis was reinforced when the Perkins Act was renewed in 2006.

At first glance, contextualization may seem most appropriate for students enrolled in career technical education (CTE) courses, formerly referred to as "vocational." Indeed contextualized mathematics at community colleges was found to include a range of disciplines, including many vocationally-oriented programs (Grubb, 2001). Not coincidentally, mathematics departments have become concerned that they are not serving the present-day needs of other disciplines "where a deep level of conceptual understanding... is deemed more valuable than a very high level of facility in manipulating symbols" (Gordon, 2006, p. 276). Departments such as biology and business often create their own mathematics courses. A community college in Hawaii, for example, intent on diversifying the ethnic profile of students admitted into its nursing program created an elementary algebra course with context-relevant mathematics problems as part of a large pre-entry, preparation program (Noone, 
Carmichael, Carmichael, \& Chiba, 2007). The implementation was still being piloted at the time of the study, with some initial positive results reported in terms of retention and success rates for the pre-entry curriculum as a whole.

Contextualization is not only appropriate for technical education courses. Some believe contextualization may become a preferred approach to teaching developmental concepts more generally, including developmental mathematics (CSS, 2009; Grubb, 2001; Office of Vocational and Adult Education, 2005). Developmental education is often seen as instrumental rather than valuable in its own right (Grubb, 2001). As a result, developmental content may be taught in ways that are not perceived as relevant or engaging. Contextualization may help to address these issues. For example, learning communities allow instructors to tailor mathematics concepts to the paired course. By some accounts, learning communities have resulted in longer persistence and in higher grades (Grubb, 2001).

In addition to enhancing student engagement and perceptions of relevance, there is recognized need for students to learn to apply mathematics concepts, particularly those related to quantitative literacy (Bransford, Brown, \& Cocking, 2000; Ganter, 2006; Steen, 2004). Unfortunately, students are often unable to apply mathematical procedures in real-world contexts. In a study of university students, for example, Gordon (2001) found that absent explicit emphasis on practical understanding, students in traditionally-taught courses were, for the most part, unable to explain the concept of slope even though they were able to procedurally calculate it. Only a third were able to 
provide an adequate "plain English" description. The aforementioned accelerated, statistics-oriented sequence could encourage the development of real-world, quantitative literacy skills

Cultural relevance, social justice, and statistics.

Contextualization through statistics represents one avenue for making course material relevant to students; cultural relevance represents another; and, of course, the two approaches are not mutually exclusive. The scant literature on mathematics acquisition through cultural relevance provides some cautionary suggestions. Earlier studies on cultural relevance in mathematics focused on assessing increased student engagement through a social justice pedagogy, noting learning gains assumed to be concomitant (Gutstein, 2003; Noguera, 2001). Enyedy and Mukhopadhyay (2007) attempted to more precisely determine the relationship between the culturally relevant material and the degree of learning.

Using a mixed methods approach, Enyedy and Mukhopadhyay analyzed a "Community Mapping Project" designed to encourage urban high school students to "recognize how mathematics is relevant to their lives and their communities" (p.140). The summer project was targeted to working class students, primarily students of color, about to begin their senior year of high school and who were interested in attending college. The project utilized computerized mapping as a means for students to examine statistics relevant to their geographic communities. The researchers quantitatively analyzed students' use of statistics to substantiate claims, and they qualitatively 
explored classroom discussions to ascertain students' beliefs about "what counts as adequate evidence" (p. 140).

The researchers found tensions between culturally relevant pedagogy and mathematics pedagogy. Often students approached inquiry assuming they already knew the truth, which led students to focus on finding supporting evidence for their claim; however, the academic goals and norms of statistics require skepticism. These conflicting norms created a tension surrounding "the project's overarching goal of advocating for a position" (p. 168). Within classroom discussions, students valued their learned experiences and observations over mathematically-constructed evidence. The researchers concluded, "As a result we saw conceptual growth around the statistical ideas they needed and hence talked about, but that growth had a ceiling" (p.168). Enyedy and Mukhopadhyay note in the study's discussion section that "cultural relevance" has multiple interpretations including the familiarity of the context of the material (i.e. content), the motivational value or application value of the material (i.e. purpose), and the familiarity of participation structures (i.e. norms). They contended that the project addressed only the first two without addressing the third component.

Unfortunately, no other studies were located which assessed the use of statistics and cultural relevance or social justice in mathematics instruction for college-level or nearly college-level students.

Learning Implications of Growth Mindset / Incrementalism

Growth mindset, as it is popularly known through nonacademic publications by 
Dweck, draws from a body of research on Theories of Intelligence (TOIs; Dweck \& Sorich, 1999). Nonacademic publications use the terminology "growth mindset" and "fixed mindset" to refer respectively to an incrementalist TOI (i.e. intelligence changes with effort) and an entity TOI (i.e. intelligence is innate and therefore fixed). Dweck's TOI framework has several implications for learning. The research in this area is extensive; therefore this section of the literature review was constrained to more recent exemplars, preferentially selecting for those pertaining to mathematics. In addition, studies which question or qualify Dweck's findings are also presented.

Research has shown that teaching students to believe that intelligence is malleable (i.e. not fixed) significantly improves their educational outcomes in mathematics. A study of $7^{\text {th }}$ grade students examined mathematics achievement during this crucial transition period (Blackwell, Trzesniewski, \& Dweck, 2007). Students with an incremental TOI expressed positive beliefs about the role of effort, were more likely to hold learning goals, and expressed less helplessness. Over four semesters, these students out-performed their entity-endorsing classmates in terms of mathematics grades. In a manipulation check, the study was conducted a second time, and an intervention was introduced whereby students were taught about TOI and implicitly encouraged to change their TOI orientation. For students whose TOI changed from entity to incrementalist, their mathematic grades improved. Students endorsing entity views evidenced declining mathematics grades.

In several studies, students with an incrementalist TOI have been shown to be 
more learning-focused (e.g., Mangels, Butterfield, Lamb, Good, \& Dweck, 2006). In contrast, students holding predominately entity beliefs were shown to be more performance-oriented. In a social cognitive neuroscience model, college students with strong entity beliefs processed information differently than peers with incrementalist beliefs (Mangels, Butterfield, Lamb, Good, \& Dweck, 2006). Students with entity TOIs had less sustained memory when corrections were provided. Perhaps as a result, their error correction was proportionally lower than incrementalist peers. The researchers assert this implies that incremental theorists may rebound better from occasional, errorrelated failures. Other recent research with college students has similarly shown that learning-focused students were more willing to take advantage of opportunities to remediate, compared to students with incrementalist beliefs who were more likely to defensively disengage and thereby forego the learning opportunity (Nussbaum \& Dweck, 2008).

The TOI framework has also been used to address stereotype threat experienced by members of marginalized populations. According to Dweck (2006), a belief in incrementalism allows students to remain engaged with challenging material despite experiencing stereotype threat. Dweck theorized this as a shift from feeling judged to focusing on a learning orientation.

A recent study by Niiya, Brook and Crocker (2010) sought to qualify the findings by Dweck et al. Their study posed the question of what occurs when college students face increasingly complex academic tasks, and some students experience 
sustained or pointed failure despite high effort. Their research underscores contextdependence, as well as revealing a "magnifying" influence associated with contingent self-worth. The researchers found, for example, that entity theorists self-handicapped by listening to detracting music on both easy and difficult tasks, but incremental theorists were marginally (but statistically significantly) more likely to self-handicap on difficult tasks. However, incremental theorists who scored high on the Contingencies of Self-Worth Scale were the most likely of all groups to self-handicap in the difficult task condition. The researchers further investigated effort and found that highly contingent incremental theorists reduced effort when initial tasks suggested high task difficulty and potential failure. The researchers assert that "motivation is fragile" and suggest confidence in succeeding may mediate effort, even under the conditions of incremental beliefs (p. 294).

Another recent, longitudinal study evaluated the implication of TOIs for students enrolled in challenging college-level STEM subject-matter at an urban college (Cromley, Tanaka, Horvat, \& Michel, 2010; Cromley, Tanaka, Horvat, \& Michel, 2011). A majority of students in the study (60\%) belonged to underrepresented ethnic groups. In examining dropouts after 18 months, the researchers found cognition (prior knowledge) and anxiety were strongly associated (large and significant differences) with whether students dropped out. However, TOIs, stereotype threat, and epistemological beliefs were not significant or appeared to have marginal impact on student retention after 18 months. This contradicted an earlier finding which suggested 
that incremental beliefs in chemistry (but not in biology) were associated with student retention through the first semester.

Qualitative analysis showed that instructors' implementation of pedagogical reforms at this urban college had limited scope and depth. Instructors "spoke about reforms in terms of relevance and interest [but] students emphasized their concerns about the pace, high expectations for independent learning, and the mismatch between the lecture and exams" (p. 7). The researcher included only selective student quotes. One quote highlighted how the pace undermined learning for understanding. Another said, "I just, I don't feel like I'm being taught. I feel like I'm being talked to and then I have to teach myself"' (p. 8).

To summarize, TOI research has implications for college students engaged in studying challenging material. The implications are as follows:

- incrementalist beliefs about intelligence are associated with higher mathematics grades,

- entity beliefs can be altered and students can be induced to hold incrementalist beliefs which positively improve their mathematics performance,

- incrementalist beliefs are associated with learning goals, compared to entity beliefs which are associated with performance goals,

- students who hold incrementalist beliefs appear to process corrective information differently - this may be associated with their higher errorcorrection rate in subsequent performance, 
- incrementalism may moderate the effects of stereotype threat, however,

- incrementalism alone is insufficient to guarantee student performance.

Regarding the last point, task difficulty and contingent self-worth both have implications for student performance, even amongst those students who believe that effort results in learning. Moreover, a recent study of students enrolled in college-level biology and chemistry suggest that TOIs do not always directly influence student retention in difficult courses.

\section{Conclusions and Needed Research}

Students entering community colleges are under-prepared in mathematics compared to four-year college and university entrants. Many students must successfully complete several mathematics courses before reaching transfer-level math. These "rungs" on the mathematics ladder substantially impact transfer rates. According to national research, each increase in high school mathematics level resulted in a $22.7 \%$ increased likelihood that community college students would transfer to a four-year institution (Adelman, 2005). Students' placement on the community college mathematics ladder depends upon high school mathematics curricula--and high school mathematics curricula is associated with ethnicity (Adelman, 2006). For example, African American and Latino students are less likely than white students to attend high schools which offered calculus.

Remediation appears to work-particularly for those students who complete the mathematics sequence at their college. By many accounts, however, only one-third of students complete all the necessary mathematics courses. The failure of the majority of 
developmentally-placed students to complete their mathematics sequence results from a number of factors. Success rates for developmental mathematics courses are typically the lowest of any courses at community colleges. Moreover, recent research shows that many students (roughly one-third) never even attempt developmental math, perhaps discouraged by the length of the mathematics sequence. Further, even students previously successful in a developmental mathematics course do not always persist to the next course in the sequence.

The often unstated underlying logic behind extending mathematics sequences appears to be related to the concept of ability-grouping, with the assumption that more students will be successful if skills-focused instruction can be narrowly targeted. A related assumption is that ability-grouped students, having been more successful as a result of the targeted instruction, will be more likely to persist in the sequence. While it is true that successful students are more likely to persist than unsuccessful students, it is also becoming apparent that further extending mathematics sequences is not likely to result in more students achieving transfer-level math.

Lessons from K-12 may be particularly instructive for community colleges seeking to improve mathematics remediation rates by reducing remedial mathematics sequence length. Reform-minded K-12 educators have been moving away from ability-grouping. Studies have found that de-tracking efforts, which increase classroom heterogeneity, can improve overall performance levels when coupled with a variety of student-centered instructional approaches (Boaler, 2008; Boaler \& Staples, 2008; Burris, Heubert, \& Levin, 
2006). Also, tracking has been shown to disadvantage underrepresented ethnic groups. Thus, an important rationale for de-tracking in $\mathrm{K}-12$ is the provision of engaging curricula for all students.

Community colleges currently employ a variety of broadly-available, traditional interventions in order to improve mathematics success rates, including peer tutoring, supplemental instruction, and the use of technology. The limited research on these interventions in community college developmental courses and sequences tends to be deeply flawed, with small samples from one college or district, often comparing only two or four semesters, with few controls applied. Yet it seems reasonable to assume, as a whole and based on the evidence to date, that these interventions offer marginal improvements at best. Comprehensive interventions such as learning communities may be more successful but are difficult at best to bring to scale.

Given the number of students affected, the depth of the mathematics remediation problem at community colleges, and the lack of proven interventions which consistently result in substantial improvements in course or sequence success rates, the increased interest in attempting to find structural remedies seem sensible. Self-paced instruction is being piloted at several community colleges; however, research-to-date does not support the notion that self-paced instruction is likely to significantly improve mathematics sequence success rates for all students. Some suggest that self-paced instruction may be more effective for adult learners over the age of 25. Similarly, accelerated refresher courses are likely to be effective for a limited student demographic. A different structural approach is 
to offer alternative mathematics pathways for students with mathematics content contextualized to their field of interest. Social justice pedagogy could be used to augment such an approach to further engage underrepresented students, but this pedagogy presents particular challenges when paired with statistics instruction. Finally, students' theories of intelligence may have implications for their willingness to engage with challenging mathematics material.

Implications for Research

At community colleges nationally, new interventions and structural modifications are being developed and piloted to remedy low mathematics sequence completion rates. These interventions and structural modifications need to be examined, both in terms of success rates and implications for pedagogy. Such research should be especially attentive to underrepresented students of color who have been the most disadvantaged by lengthy developmental mathematics sequences.

In particular, research is needed to investigate whether and how shortened and accelerated mathematics sequences can be successful in retaining students, as well as successful in supporting the learning of rigorous academic content. In addition, contextualization has been proposed as means of motivating community college students enrolled in developmental mathematics, but there is limited research on the effectiveness of such approaches. One possible accelerated mathematics pathway consists of teaching developmental mathematics and algebra concepts and procedures required as preparation for a college-level statistics course, rather than calculus. This contextualization may be 
appropriate for students who are not oriented toward math-intensive fields, but who need quantitative literacy skills. The scope of procedural knowledge can be curtailed to those skills needed for statistics, allowing for deeper learning of fewer concepts. Contextualized learning may be particularly attractive to community college students who tend to be pragmatic in their views of higher education. 


\section{Chapter Three: Methodology}

A mixed methods, case study approach was used to analyze a local community college's implementation of an open-entry, two-course mathematics sequence culminating in transfer-level statistics. The sequence, called StatMode (a pseudonym), reduces the number of courses students need to take in order satisfy the mathematics requirements for transfer to a four-year institution. At the time the study began, the sequence was a pilot; during the timeframe of the study it was approved by the department. Enrollment includes students who placed into the lowest level of mathematics that the college offers (i.e. arithmetic); as such, the sequence attempts to support all students, regardless of initial placement or mathematics eligibility, in reaching college-level statistics by the end of the second semester. In addition to being open-entry, this sequence traditionally is comprised of a high proportion of Latina/o students (roughly $80 \%$ ) due to a cultivated relationship with the college's Puente program, with roughly $70 \%$ indicating they are the first in their immediate family to go to college.

Given the then-pilot nature of StatMode, the small number of participants, and the inclusion of a single instructor in the study, a quan $\rightarrow$ QUAL explanatory mixedmethods approach was selected. The primary quantitative research question posed by this study was whether underprepared students from underrepresented groups could successfully complete an accelerated mathematics sequence. Given the two semester 
sequence design and the demographics of the students enrolled in the sequence, this study was well positioned to respond to this question. A further strength of the study was the incorporation of results corresponding to a nationally-normed introductory statistics post-test. These quantitative results were used to confirm students' achievements in StatMode with regard to two specific introductory statistics domains: (a) data exploration and descriptive statistics, and (b) probability and inference.

Qualitative propositions were investigated to explain the quantitative findings. Through student interviews, triangulated with classroom observations and discussions with the course instructor, the researcher was able to ascertain and verify some aspects of this particular implementation of an accelerated mathematics sequence which seemed important to students. As with the quantitative data, qualitative data were examined for demographic differences in an effort to clarify potential transferability.

The remainder of this chapter describes the study design in greater detail and delineates each research question or proposition. The chapter also addresses standard areas such as the role of the researcher, ethics, and the treatment of data in terms of both collection and analysis. Due to the importance of questions about possible transferability and the emphasis on the qualitative analysis, the study context and participants are described in detail. The section describing participant selection outlines two groups of students which were followed through much of the qualitative analysis: (a) a younger, primarily first-generation Latina/o group, and (b) a smaller group 
composed primarily of African American women who were somewhat older than the young Latina/os.

\section{Study Design}

The mixed methods design utilized concurrent data collection; however, the data analysis followed an explanatory approach with an emphasis on the qualitative data. This type of explanatory approach, as described by Creswell and Plano Clark (2007), typically privileges the quantitative data (denoted by QUAN $\rightarrow$ qual). This case study, though, used a quan $\rightarrow$ QUAL analytic approach for the following reasons. The study focused on a new, pilot mathematics sequence with an instructor who is recognized within her field as highly effective and deeply invested in the pilot's success. In other words, the case for this study (i.e. the StatMode sequence) was selected because it is atypical. As Bodgan and Biklen (2008) caution, such selection limits the generalizability of the findings. More specifically for this case study, the strength of the study does not reside with the quantitative analysis due to severe generalizability limitations. In fact, the quantitative analysis was only necessary insofar as it showed whether such an approach is possible, i.e. whether it can be implemented effectively, not whether it is likely to be effective under typical conditions. Insight and potential for transferability emerged from the qualitative analysis.

\section{Role of the Researcher}

The researcher developed a working relationship with the StatMode instructor, 
beginning approximately one year prior to the commencement of the study. The researcher and instructor had several key acquaintances in common which facilitated the establishment of a working relationship. In addition, the relationship was facilitated by the fact that the researcher's coworker had published mathematics sequence completion findings several years ago which partially instigated and informed the instructor's local research leading to the creation of StatMode. As a result, it was clear to the instructor from the onset that the researcher is part of a research community which has an enduring interest in studying how student movement through mathematics might be improved. The researcher regularly apprised the instructor of study details. Continued trust between the researcher and the instructor was critical to the successful completion of the study.

The researcher maintained a reflective journal in order to track emerging understandings and in order to document preconceptions against which findings can be compared. Journal entries were either typed or audio-recorded after each data collection episode (student interviews and/or classroom observations) and after substantive conversations with the instructor. Pivotal changes in the researcher's observations were recorded. Equally importantly, and unexpectedly, the entries allowed the researcher to document triangulation (or disconfirmations) between her preliminary findings and the instructor's observations. This was unexpected as the degree of access to and rapport with the instructor was unanticipated. As such, the journal entries also provided a space 
for the researcher to regain more neutral intellectual territory. The enthusiasm of the students as well as the instructor regarding this pilot course sequence was palpable. Journal entries provided a conscious mechanism for the researcher to reflect on and examine personal biases. Critical colleagues, the faculty advisor, and dissertation committee members also assisted in reviewing the findings for credibility. In combination, these efforts allowed the data to be viewed more fully, from multiple angles.

Once data collection began, the researcher tracked interview data with an electronic cataloging system utilizing student pseudonyms. Dates and times for all interviews were recorded in the filenames. Classroom observations were logged using a standard observation format.

\section{Research Objectives}

\section{Quantitative Hypotheses}

Quantitative hypotheses focused on course completion measures, sequence persistence rates, and sequence completion rates, as well as test performance. The primary hypothesis was that a large majority of students in StatMode would be able to complete the initial course successfully and persist to the second, transfer-level course-compared to a minority of similar students nationally. A related hypothesis was that success rates will be proportionally reflective of the student composition in StatMode; that is, Latino and other underrepresented students would be as successful as 
their white peers. Due to the composition of the StatMode group, the research was unable to fully investigate this hypothesis; however, it was addressed to the extent possible. Quantitative analysis was used to investigate success rates for students entering StatMode with the lowest level of mathematics skills to those students who enter with higher level mathematics skills. Additional demographic variables of gender, age group, and Puente status were also examined for potential relationship to student success in the sequence

Quantitative analysis of items from the Comprehensive Assessment of Outcomes in a First Statistics course (CAOS) test was used to ascertain students' knowledge with regard to two specific introductory statistics domains: (a) data exploration and descriptive statistics, and (b) probability and inference. The hypothesis associated with CAOS items was that StatMode students would perform equal to their national peers on the post-test items. These results were examined by the aforementioned demographic variables.

A final quantitative data item derived from the use of the Adult Dispositional Hope Scale (ADHS). The scale is comprised of twelve statements total which students self-rated, including four statements regarding individual determination to meet goals (i.e. agency), four statements regarding individual ability to produce the means for attaining the goals (i.e. pathways), and four distracter statements. While initially presented in the quantitative section, this scale was used only with StatMode 
interviewees (a subset of the course). The primary use of the ADHS was to determine whether StatMode students may be atypical with regard to their hopefulness. The hypothesis was that StatMode students were not substantially different than their peers at other colleges regarding their sense of pathways and agency. While students' selfselection into StatMode cannot be fully accounted for, this analysis helps to investigate the potential impact of self-selection.

Qualitative Propositions

The qualitative data sought to explore, from the students' perspective, the reasons why StatMode might be effective. Collected primarily through individual student interviews, triangulated with classroom observations and discussions with the instructor, the qualitative data examined students' experiences in the pilot mathematics sequence. Data collection focused on the following:

- students' feelings and beliefs about mathematics and the nature of the mathematics concepts they are learning,

- perceived relevance of the content, including contextualization through statistics and cultural relevance, and

- shifts in students' sense of competency with regard to learning and using mathematics concepts.

Other aspects of StatMode were also investigated for conscious saliency to the students, including propositions that the following attributes contribute to students' willingness to persist through challenging mathematics material:

- caring relationships between the instructor and the students; 
- early, encouraging feedback from the instructor; and

- $\quad$ peer support, particularly that derived from the learning community associated with Puente.

Finally, a potential criticism of StatMode was explored. This criticism reflects the conundrum that StatMode may be viewed as a tracking mechanism or a detracking mechanism, depending on one's perspective. StatMode can be viewed as a detracking effort, bringing developmentally-placed students rapidly into college-level content. Simultaneously, StatMode may track students away from mathematics-intensive and science-related majors. To better understand this issue, from the students' perspectives, students' statements about mathematics sequences were analyzed. The related qualitative proposition was that community college students would be inclined to view StatMode as a detracking mechanism.

\section{Context}

Martinez Community College (MCC) (pseudonym) is located in a suburbancommercial county that has been rapidly increasing in population density. Between 1990 and 2000 , the population increased by $40 \%$ in the region where the college is located. The proportion of Asian and Latino residents has been increasing. Compared to the surrounding area, the city in which MCC is located has a low bachelor's degree level: $15 \%$ of adult residents had obtained a bachelor's degree or higher, compared to $38 \%$ immediate the county, and as high as $54 \%$ in neighboring counties. In addition, according to 2005 data, the college is situated next to one of 
the lowest performing high schools in the surrounding area. The proportion of underserved students was one rationale for selecting this site for the study.

The site was also selected because at the time this study began it was one of few colleges offering a two-course sequence to accelerate community college students to and through introductory, college-level statistics. Since the inception of the study, several colleges have begun employing similar accelerated statistics sequences-some collectively under the aegis of the Carnegie Foundation for the Advancement of Teaching and others through more localized approaches.

Another important aspect of the context was the situation of the StatMode pilot within the mathematics department. At the onset of the study, the sequence was a pilot. By the completion of the study, the sequence was voted by the department to be continued on a non-pilot basis. Students in the study were aware that this negotiation and discussion within the department was occurring. In order to gauge and control for the impact this had on students' perceptions of the sequence, a question was included in the study asking students directly about their experiences vis-à-vis being in a "pilot" class.

Finally, before revealing more about students' demographics in the next section, it is important to acknowledge that the instructor for StatMode was a white woman. At the time of this study, she was already a longtime mathematics instructor at MCC. She will be referred to by her pseudonym: Sylvia. 


\section{Student Demographics Pertaining to Quantitative Analysis}

To better understand the study population, demographic interactions were investigated. Due to the small sample size $(N=29)$ and frequent occurrence of cells with zero cases, the Fisher's Exact Test was used rather than the Chi-Square Test for Independence. Also due to the small sample size, a higher $p$-value $(p<0.1000)$ was used for these significance tests--and all subsequent statistical significance tests throughout the study.

Just one interaction between the demographic variables was found to be significant: age group and Puente (Fisher's Exact test $>0.0000$ ). All Puente students were under 18 or 19 years old. In comparison, only $25 \%$ of Non-Puente students were under 20. No other demographic crosstabulations even approached statistical significance.

The statistically significant relationship between age group and Puente status is particularly important to understanding rival hypotheses vis-à-vis the quantitative analysis. StatMode demographics were incorporated into the quantitative analysis and presented in Chapter Four. Due to the small sample, findings associated with Puente could not be subjected to age controls.

\section{Participant Selection for Qualitative Analysis}

In order to maximize the investigation of the broadest range of student experiences, no a priori sampling was used. All 29 students enrolled in StatMode were 
solicited for interviews. The instructor introduced the researcher to StatMode students during a normal class session. Due to the nature of the class, the instructor used the opportunity to briefly describe the dissertation process and study design to students. Students had already been introduced to the concept of designing studies. Students were informed that they would be solicited to participate on a voluntary basis. Volunteers placed their names on a sign-up sheet maintained by the instructor.

The face-to-face interviews occurred during three days in November 2010. Interviews took place during class time to minimize inconvenience and facilitate participation and ranged in length from 35 to 45 minutes. A private office was used to provide confidentiality. The interview dates were selected by the instructor in order to minimize any disruption of the class or the students' learning. The initial six interviews occurred on November 4. The subsequent five interviews occurred on November 16 and 18. Due to early saturation of emerging themes, the interviewees were limited to the initial 11 volunteers.

Eight of the students interviewed were Latina/o, of whom five were male and three identified as Latina. The other three interviewees identified as African American women, one of whom also indicated a bi-racial background. The ages and demographic backgrounds of these groups (Latina/o and African American) were relatively distinct, as will be described below. In addition, the representativeness of the interviewee selection will be discussed. 
Interviewee Representativeness

The eleven interviewees were representative on all student demographics except gender. Interviewees did not differ significantly from their StatMode cohort with regard to ethnicity, age group, mathematics eligibility, or Puente status. The proportion of male students interviewed approached statistical significance (Fisher's Exact $=$ $0.1081)$.

Although student performance in the sequence was not known at the time of interviewee selection, the instructor attempted to ensure that a range of students were included based on their performance to date. Indeed, per subsequent analysis, the interviewees did not differ significantly from their classmates on any of the course, sequence, or CAOS outcome variables.

\section{Latina/o Group and Outlier}

Of the eight Latina/o students interviewed, nearly all were still teenagers and in their first semester at MCC. Seven of the eight Latina/o students were 17, 18, or 19 years old. These same seven students had just matriculated into their first semester of college, except one of the seven who was in his second semester at MCC. All seven were enrolled in Puente. None had prior college experience (excluding in some cases concurrent enrollment as high school students).

Most of the Latina/o interviewees were first generation both in terms of U.S. citizenship and college education. None had a parent with a four-year college degree. 
Four students had both parents with a high school diploma or less; the other four students indicated one parent with high school diploma or less, but the second parent had some college experience. Only one student indicated a parent who had achieved a college degree, which was from a community college. Regarding nationality, seven of the eight Latina/o students had parents who were educated outside the U.S., with Mexico the most commonly cited country. Four of the students indicated that both parents received their education in Mexico; other countries indicated were Belize, Nicaragua, and Peru.

One Latino student was a demographic outlier. Manny (pseudonym) was in his fifth semester at MCC. He was not enrolled in Puente. He was 25 years old. He was also the only Latina/o student who had both parents educated in the U.S., although neither parent had college experience. The self-selected pseudonyms of the other Latina/o students were as follows: Guss, Spaceman, Teavo, Davina, Jessie, Wolf, and Micky.

\section{African American Group}

When compared to most of the Latina/o students, the three African American women were older (ages 22, 32, and 35), had more previous college experience, and came from families with more formal education. Each of these students had one parent with a four-year degree, and in all cases, both parents educated in the U.S. All three had prior college experience themselves. In fact, all three had attended another college 
prior to enrolling at MCC. In addition, two were in their fifth semester at MCC. The youngest was only in her second college semester at $\mathrm{MCC}$, but she had previously attended a four-year institution. Their self-selected pseudonyms for this study were Linda, SkyMarie, and Jackie. Figure 1 provides a summary reference regarding interviewee demographics. 


\begin{tabular}{|c|c|c|c|c|c|c|c|c|}
\hline$\#$ & $\begin{array}{c}\text { Self- } \\
\text { Selected } \\
\text { Pseudonym }\end{array}$ & Age & Sex & $\begin{array}{l}\text { Ethnicity } \\
\text { (As Indicated by } \\
\text { Student During } \\
\text { Interview) }\end{array}$ & $\begin{array}{l}\text { In } \\
\text { Puente? }\end{array}$ & $\begin{array}{l}\text { New* } \\
\text { to } \\
\text { College? }\end{array}$ & $\begin{array}{l}\text { Parent(s) } \\
\text { Educated } \\
\text { in U.S. ?** }\end{array}$ & $\begin{array}{c}\text { Parent(s) } \\
\text { College } \\
\text { Degree?** }\end{array}$ \\
\hline 1 & Guss & 19 & $M$ & Latino/Hispanic & Yes & Yes & & \\
\hline 2 & Spaceman & 18 & $M$ & Hispanic & Yes & Yes & Mother & Mother (CC) \\
\hline 3 & Teavo & 18 & $M$ & Latino & Yes & Yes & & \\
\hline 4 & SkyMarie & 32 & $\mathrm{~F}$ & $\begin{array}{l}\text { African American/ } \\
\text { Caucasian }\end{array}$ & No & No & Both Parents & Father (4 yr) \\
\hline 5 & Manny & 25 & M & Hispanic & No & No & Both Parents & \\
\hline 6 & Davina & 18 & $F$ & Latin & Yes & Yes & Mother & \\
\hline 7 & Jackie & 35 & $F$ & African American & No & No & Both Parents & Father (4 yr) \\
\hline 8 & Jessie & 18 & $F$ & Latina/Hispanic & Yes & Yes & Father & \\
\hline 9 & Wolf & 18 & $M$ & Latino & Yes & Yes & & \\
\hline 10 & Micky & 18 & $M$ & Hispanic & Yes & Yes & & \\
\hline 11 & Linda & 22 & $F$ & African American & No & No & Both Parents & Mother (4 yr) \\
\hline
\end{tabular}

\section{Notes:}

Light gray shading identifies African American students.

Darker shading with graduated fill effect identifies Latino outlier.

* New to College defined as first or second MCC semester, with no experience at another college.

** If neither parent, then blank.

Figure 1. Demographic overview of interviewees, ordered by interview. 


\section{Ethics and Protection of Human Subjects}

The nature of the study required no deception of either students or the faculty member. Ethical considerations related to this study included risks to participants and to the instructor of the pilot. For participants, one potential risk was loss of privacy. This risk has been minimized by using pseudonyms and keeping all research data in a secure location. Each participant was assigned a pseudonym known only to the researcher. Academic records associated with this pseudonym were stripped of any personally identifiable information. For participants, there was also a psychological risk of discomfort during the interview process. Participants were informed that they could refuse to answer any question, stop the interview at any time, and withdraw from the study at any time.

The primary risk to the instructor continues to be the potential reflection of negative findings on her professional reputation. This serious risk largely results from the relative uniqueness of the pilot sequence. These concerns were mitigated by the instructor's own commitment to making data about the pilot public. Concerns were also mitigated by working closely with the instructor. Insights were shared with the instructor in order to triangulate findings but also in order to identify any potential differences in perspective which might need to be elaborated on in the analysis.

\section{Data Collection and Instrumentation}

This mixed methods case study utilized both quantitative and qualitative data. 
Quantitative data were gathered by the instructor during regular instructional assessments. These data included standard course completion, sequence persistence, and sequence completion measures paired with de-identified demographic data. In addition, the instructor administered the Comprehensive Assessment of Outcomes in a first Statistics Course (CAOS) test as part of her regular instructional practice. Data were de-identified in accordance with IRB protocols prior to being made available for analysis. The nationally-normed CAOS exam is described in more detail in Chapter Four.

Qualitative data were gathered by the researcher primarily through semistructured student interviews over a four week span during the fall 2010 semester. Interviews were augmented by and triangulated with classroom observations and discussions with the instructor. Interviews lasted roughly 40 minutes per student. Classroom observations lasted two to four hours each. Discussions with the instructor ranged from ten minutes to 90 minutes.

The qualitative interview instrument was initially developed by and used by the researcher with a previous group of ten developmental mathematics students engaged in an intensive mathematics program. Researcher-developed instrumentation was necessary because the StatMode pilot is unique and comprised of relatively novel components (e.g., acceleration). The instrument was modified for the current context. In addition, after the first day of interviews, two 
themes quickly emerged. To address these themes, two additional questions were added to the interview protocol and asked toward the end of the interview, if not already discussed. The ADHS was also deployed during the interview. This commonly available instrument has been described in more detail in Chapter Four.

\section{Validity and Transferability}

The qualitative data collection was limited by three factors in particular: the short timeframe of the collection, students' minimal exposure to the researcher, and the fact that the researcher differed demographically from the students. Regarding the first factor, logistically the short collection timeframe did not allow for techniques such as ongoing, modified analytic induction (Bogdan \& Biklen, 2008). While some questions were added mid-collection, the timeframe did not allow for the in-depth analysis to occur between subject interviews in such a way that could inform more substantial modifications and refinements to the collection protocol. Regarding the second two factors, one clear distinction between the researcher and the students was ethnicity. The researcher is white and all the students interviewed were students of color. This coupled with the short data collection timeframe meant that some sensitive questions regarding race/ethnicity were only partially investigated since students could not be assumed to be forthcoming under the research conditions.

The qualitative data collection was potentially affected by another factor as well: students' knowledge about the pilot status of the program. This was both beneficial and 
potentially compromising. It was beneficial due to the fact that it made students keenly aware of the circumstances of the pilot and this made them more reflective than might otherwise be the case. It also meant that they saw themselves to some extent as advocates for the two-course sequence, possibly curtailing any negative comments. There was also a potential Hawthorne Effect from being in a pilot which was studied by this researcher, observed by other instructors, and, most pointedly, being evaluated within the college's own mathematics department. This was anticipated and questions were built into the interview protocol so that the potential impact could be investigated, i.e. students were asked directly about the experience of being in a pilot under scrutiny. Moreover, classroom observations were used to triangulate findings.

Three additional factors likely facilitated the richness of the qualitative data collection within the short timeframe of the study: students' relationship to their instructor, the instructor's vouching for the researcher, and the instructor's emphasis on students' metacognition within the instructional process. As the qualitative analysis shows, students expressed a certain gratitude toward and appreciation for the instructor. Since the researcher did not have sufficient time to develop rapport with the students, their respect for their instructor (who introduced them to the researcher) served to facilitate students' willingness to talk with the researcher. This also meant that students might be protective of the pilot due to loyalty to the instructor. This potential protectiveness was likely mitigated due to the nature of the class subject itself which 
emphasized analytical thinking and honest scrutiny. In addition, the instructor's general instructional approach encouraged students' willingness to be forthcoming. Moreover, questions were built into the interview protocol so that this potential impact could be investigated, i.e. negative perceptions were explicitly solicited, and classroom observations were used to triangulate findings.

Regarding the third facilitator of collecting rich qualitative within a short timeframe, the emphasis on metacognition was apparent as students discussed the instructional design. The researcher's prior experience conducting interviews with mathematics students in the initial design of the interview protocol was that students were often not especially articulate about the nuances of the learning experience; thus, many follow up questions were required to elicit well-rounded information. In contrast, StatMode interviewees were exceedingly forthcoming.

Threats to validity associated with mixed methods designs were minimized through the use of a single study population; in other words, the subjects for the qualitative and quantitative analyses were the same. Creswell and Plano Clark (2007) indicate this is particularly important for an explanatory mixed methods design. In addition, care has be taken, as urged by Collins, Onwuegbuzie, and Jiao (2007), to be mindful of issues pertaining to interpretive consistency between the quantitative and qualitative findings. As appropriate, negative case analysis, described by Caracelli and Greene (1993), was used to provide disconfirming evidence and to develop refinements 
in the researcher's conceptual understanding.

Issues of generalizability and transferability remain pronounced due to the fact that the study focuses on a particular, self-selected cohort taught by a single, highlyinvested instructor. Findings related to course content (e.g., statistics contextualization) and sequence acceleration are probably the most easily transferable. Structural changes to alternative mathematics sequences are not instructor-dependent. Any college could elect to create such a sequence and identify faculty to teach it. In addition, the proportion of students electing to enroll in statistics to complete their transfer requirements has been increasing - so student interest in shortened statistics sequences is likely to be high, making such a sequence viable institutionally. Results at other institutions might not be as positive as those presented in this study; however, for an open-entry model to improve upon the national figures for students reaching collegelevel mathematics, the completion rate for the pre-statistics course need only be higher than the $33 \%$ cited in the literature review. Note, this does presume that a substantial percentage of students could subsequently pass a transferable statistics course and perform competently.

In terms of student self-selection, the study design limits implications for overarching generalizability. There is no basis for claiming that all non-STEM students would benefit from this type of sequence restructuring. However, while the findings might not apply to all community college students, they likely apply to some students at 
all institutions. In other words, positive outcomes do not make a case for converting all non-STEM math pathways to a StatMode model. Instead, positive findings suggest that such an option should be provided.

To the extent that the data will allow, some suggestions have been made in the Chapter Seven regarding which students might be most likely to benefit from sequence restructuring. However, these implications are suggestive only since the study's findings were limited by the small sample size and general homogeneity of the sample. In this regard, the qualitative data were richer than the quantitative data and have implications for how and why, from the students' perspectives, an accelerated statistics sequence can be effective.

In terms of the instructional approach and classroom environment, any replication of this sequence would not, presumably, merely mimic the instructor's course design and instructional approach. Individual instructors must find ways to interact with students which are authentic to them and viable for them, and appropriate for their students. Affective characteristics of the instructor-student interactions and student-student interactions are likely to be the most difficult to genuinely replicate. Students' insights can be potentially instructive in this regard, suggesting what might be most important and why.

To promote transparency regarding students' voices, themes drawn from the qualitative data analysis were substantiated with multiple data points and detailed 
evidence. The intent was to ascertain not only what the instructor was doing but also how it impacted students. In addition, discrepant cases were often highlighted as counterpoints to provide further insight.

\section{Data Analysis}

Quantitative analyses were performed in SAS. The Fisher's Exact Test was used throughout instead of the Chi-Square Test for Independence due to the small sample size and frequent occurrence of cells with zero cases. Standard frequencies and percents were used to show the overall course success, sequence persistence, and sequence success rates. In addition, a categorical variable was created to examine the proportion of students who received a different letter grade in the second semester (i.e. "higher," "lower," or "same"). Letter grades were converted into mean GPAs and compared across groups using the Wilcoxon Rank-Sum Test. Note, $t$-Tests were not employed due to the small sample, large variances, and non-normal distribution. CAOS data were also analyzed using this approach. All data were subjected to tests to determine whether demographic variables appeared to be significantly associated with student outcomes.

Qualitative data were coded for themes, and then further summarized into broad categories (Bogdan \& Biklen, 2008). Glossing was used to isolate and code emergent themes after the first day of interviews, and the interview protocol was amended as previously described. After all interviews were complete, the audio-recordings were transcribed professionally. To capture tone and allow greater authenticity, transcriptions 
were precise and included utterances such as "umm" and "yeah." The accuracy of each transcription was verified by the researcher. Coding and theme analysis were conducted "by hand," without the use of text-mining software, so the researcher could maintain close proximity to the nuances in the data collected. Apparent outliers were investigated further to ensure that key themes were not missed due to oversight or researcher bias.

Qualitative and quantitative data were mixed during several stages including question formulation, data collection and analysis. The final analysis incorporated triangulated quantitative data, transformed qualitative data, and qualitative quotes. The overall analysis emphasizes the qualitative findings including findings which appear to have the most explanatory power for the group overall, findings which distinguish between subgroups within the population, and findings which raise potent questions about students' experiences.

\section{Summary}

A mixed-methods approach was employed due to the pilot nature of this curricular intervention. This design was drawn from a pragmatic research framework and focused on the urgent need to improve mathematics sequences for community college students. While there was not a sufficient sample size within the pilot for a fullscale quantitative study, the quantitative data were necessary to justify the importance of the qualitative findings. The qualitative analysis was vital to investigate the qualities within the StatMode sequence and instructional design which supported students' 
success and achievement. Due to the unique context and to counterbalance subjectivity, a variety of both quantitative and qualitative data were gathered for corroboration and triangulation in order to present the most complete picture possible of this particular case. 


\section{Chapter Four: Quantitative Findings}

As hypothesized, a large majority of StatMode students were able to complete the initial pre-statistics mathematics course successfully, persist to the transfer-level statistics course, and successfully complete transfer-level statistics. Of the initial cohort $(N=29)$ enrolled in the pre-statistics mathematics course, $93 \%(n=27)$ completed the first semester with a grade of $\mathrm{C}$ or higher based on a 4.0 scale. All 27 persisted to the second semester statistics course, of whom 25 completed the statistics course with a grade of $\mathrm{C}$ or higher. Of the initial cohort of 29 , the 25 completers represent an $86 \%$ completion rate for the two-course mathematics sequence overall.

Students from a range of incoming mathematics levels and diverse ethnicities successfully completed the full two-course sequence. Ten students entered at the lowest mathematics levels, i.e. eligible to enroll in arithmetic or pre algebra. Of these ten students, $80 \%(n=8)$ completed both courses with a grade of $\mathrm{C}$ or higher. Of the initial cohort, nearly all students $(n=28)$ were students of color-primarily Latina/o and African American. The overall success percentage for students of color was $86 \%(n=$ 24). All 17 students concurrently enrolled in Puente successfully completed both semesters with a $\mathrm{C}$ or higher. Some differences in student outcomes were statistically significant when Puente students were compared to Non-Puente students.

At the end of the second semester, StatMode students performed similarly to or outperformed a national sample of students in a first statistics course. StatMode 
students were assessed using questions from a nationally-normed exam--the Comprehensive Assessment of Outcomes for a first course in Statistics (CAOS). The instructor divided questions into two broad learning domains: (a) data exploration and descriptive statistics and (b) probability and inference. For the descriptive statistics section, based on the eight questions with the highest level of discrimination $(>.35)$, StatMode students from the initial cohort who completed the final exam scored somewhat better than the national average. On average, StatMode students answered $61 \%$ of these questions correctly, compared to $53 \%$ for students from the national sample. For the probability domain, five questions had discrimination level above .35 . For these questions, StatMode students had a mean performance of $50 \%$, compared to the national mean of $49 \%$.

Finally, the students who were interviewed $(N=11)$ were asked to complete the Adult Dispositional Hope Scale (ADHS). These interviews occurred toward the end of the first semester, after students had significant exposure to the course. Students scored relatively high on both parameters of the ADHS: pathways and agency. Students met the criteria determined by the ADHS developer for having "high hope": a score of 24 or higher (Snyder, 1994). StatMode interviewees had mean hope scores of 28, equally distributed between pathways (score of 14) and agency (score of 14).

\section{The Quantitative Findings}

Several student outcomes were examined, including success in the pre-statistics 
course by grade, success in the statistics course by grade, overall success in the sequence by average GPA, and the change in students' grades between the first semester and the second semester. For the latter variable, the categories were "higher," "same," or "lower." In addition, fall and spring grades were coded into "dummy" variables were "yes" indicated passed with a $\mathrm{C}$ or higher, and "no" indicated otherwise. All student outcomes were examined by all demographic variables available, including gender, age group (divided into two groups--under 20 or 20 and older--since specific age was not known for all students), mathematics eligibility, and Puente status. Mathematics eligibility level was based upon students' score on the MCC placement test or their most recent successfully completed mathematics class. Note, at MCC there is no prerequisite for pre algebra, so at MCC the distinction between arithmetic and pre algebra is considered somewhat artificial. To further examine mathematics eligibility, this variable was recoded into "lower" and "higher" categories, where lower included arithmetic and pre algebra, and higher included elementary and intermediate algebra. All tests were run using both the four-category variable and the two-category variable. Student outcomes by age group, gender, and mathematics eligibility were not statistically significant; however, the relationships between Puente status and most student outcomes variables were found to be statistically significant. This significance testing for Puente will be presented in detail later in this chapter. As a reminder, there were no statistically significant interactions between the demographic variables, as 
described in the methodology chapter, with one exception: age group and Puente status.

The Fisher's Exact Test was used to determine statistical significance, rather than using the Chi-Square Test for Independence, due to the small sample size and frequent occurrence of cells with zero cases. To further example statistically significant results pertaining to Puente, the nonparametric Wilcoxon Rank Sums and KruskalWallis tests were used to examine the combined GPA representing student performance in both semesters. These tests were used as an alternative to the $t$-test due to the extreme differences in the variances between the Puente and Non-Puente groups, the non-normal distributions, and the small sample size. Due to the small sample size, $p<$ 0.1000 was used.

Due to the small $\mathrm{N}$ which limits the power of statistical tests, frequencies for student outcomes by demographic variables will be presented in the following sections despite the lack of statistical significance. The primary quantitative research question posed by this study was whether underprepared students from underrepresented groups could successfully complete an accelerated mathematics sequence. Even when not statistically significant, the data presented show the range of outcomes students experienced.

To reiterate, the reader should understand that the relationships between the demographic variables and student outcomes presented in the following tables were not statistically significant unless explicitly identified as such. 


\section{Pre-Statistics Course Success for Initial Cohort}

An initial cohort of 29 students enrolled in the pre-statistics course in fall 2010, as of the MCC census date. Of those, 27 completed the first semester with a grade of C or better. Two students withdrew from the course and consequently received a $\mathrm{W}$ notation on their transcripts. Table 1 shows the final grades in the pre-statistics course by three demographics: gender, age group, and Puente status. Most students across all demographic groups successfully completed the pre-statistics course with a $\mathrm{C}$ or better.

Ethnicity is not presented in Table 1 as specific ethnicity was unknown to the researcher and the instructor for several of the students. However, all students except one were identifiably students of color-primarily Latina/o or African American. Only one white student enrolled in StatMode. The two students who withdrew during the first semester were both African American women and both more than 20 years old. Two other African American women, also more than 20 years old, remained in and successfully completed the pre-statistics course. 
Table 1

Final Grade in Pre-Statistics Course by Gender, Age Group, and Puente Status

\begin{tabular}{|c|c|c|c|c|c|c|}
\hline \multirow[b]{2}{*}{ Final Grade } & \multicolumn{2}{|c|}{ Gender } & \multicolumn{2}{|c|}{ Age Group } & \multicolumn{2}{|c|}{ In Puente? } \\
\hline & Female & Male & $<20$ & $20+$ & No & Yes \\
\hline A & $15 \%$ & $0 \%$ & $5 \%$ & $22 \%$ & $17 \%$ & $6 \%$ \\
\hline B & $50 \%$ & $56 \%$ & $60 \%$ & $33 \%$ & $25 \%$ & $71 \%$ \\
\hline C & $25 \%$ & $44 \%$ & $35 \%$ & $22 \%$ & $42 \%$ & $24 \%$ \\
\hline W & $10 \%$ & $0 \%$ & $0 \%$ & $22 \%$ & $17 \%$ & $0 \%$ \\
\hline $\mathrm{N}$ & 20 & 9 & 20 & 9 & 17 & 12 \\
\hline
\end{tabular}

Fisher's Exact for Pre-Statistics Final Grades by Puente: $p=0.0472$

Given the small cohort, Table 1 will be discussed in broad terms. The data show that, in general, both male and female students successfully completed the course. However, female students represented all the A grades and the only Ws received in the pre-statistics course. Similarly, students from both age groups successfully completed the course. However, students in the 20 and older age group received more As and the only Ws. Finally, the difference in grade distributions between Puente and Non-Puente students was statistically significant. Both Puente students and Non-Puente students were generally successful in the course. However, students not in Puente received more As, more Cs, and the only Ws.

Table 2 shows the pre-statistics course success rates by students' incoming mathematics level, i.e. eligibility level. 
Table 2

Final Grade in Pre-Statistics Course by Mathematics Course Eligibility

\begin{tabular}{lccccc}
\hline Final Grade & Arithmetic & Pre algebra & $\begin{array}{c}\text { Elementary } \\
\text { algebra }\end{array}$ & $\begin{array}{c}\text { Intermediate } \\
\text { algebra }\end{array}$ & Total \\
\hline A & $0 \%$ & $0 \%$ & $27 \%$ & $0 \%$ & $10 \%$ \\
B & $33 \%$ & $57 \%$ & $36 \%$ & $75 \%$ & $52 \%$ \\
C & $67 \%$ & $43 \%$ & $18 \%$ & $25 \%$ & $31 \%$ \\
W & $0 \%$ & $0 \%$ & $18 \%$ & $0 \%$ & $7 \%$ \\
\hline $\mathrm{N}$ & 3 & 7 & 11 & 8 & 29 \\
\hline
\end{tabular}

The data in Table 2 show that students from a range of incoming mathematics levels were successful in the pre-statistics course. Students with arithmetic placements did earn the largest percentage of Cs. When As and Bs are subtotaled, a potential pattern emerges: completions with $\mathrm{A}$ or $\mathrm{B}$ grades range from $33 \%$ at the arithmetic level, to $57 \%$ for pre algebra, $64 \%$ for elementary algebra, and $75 \%$ for intermediate algebra. However, this pattern is not statistically significant. Moreover, students with elementary algebra eligibility show the greatest spread in grades, earning the only As and the only Ws.

\section{Statistics Course Success for Initial Cohort}

All 27 students who completed the first semester pre-statistics course persisted to statistics, and 25 completed statistics with a grade of $\mathrm{C}$ or higher. The data in Table 3 and Table 4 show that students across all demographic groups successfully completed 
statistics with a $\mathrm{C}$ or better. Of the two students who received Ds, one was male, one was female, neither were enrolled in Puente, both were under 20 years old, and, both began the fall 2010 semester at the pre algebra level. Note, two students opted to take the statistics course with a different instructor. One student joined Umoja, a program which seeks to serve primarily African American and first-generation college students through culturally relevant curriculum and academic support services. Another, for convenience, selected a course section at a separate campus. The StatMode instructor continued to monitor their progress and their statistics course grades are included in the data that follows.

Table 3

Final Grade in Statistics Course by Gender, Age Group, and Puente Status

\begin{tabular}{|c|c|c|c|c|c|c|}
\hline \multirow[b]{2}{*}{ Final Grade } & \multicolumn{2}{|c|}{ Gender } & \multicolumn{2}{|c|}{ Age Group } & \multicolumn{2}{|c|}{ In Puente? } \\
\hline & Female & Male & $<20$ & $20+$ & No & Yes \\
\hline A & $33 \%$ & $11 \%$ & $20 \%$ & $43 \%$ & $30 \%$ & $24 \%$ \\
\hline B & $50 \%$ & $33 \%$ & $50 \%$ & $29 \%$ & $20 \%$ & $59 \%$ \\
\hline C & $11 \%$ & $44 \%$ & $20 \%$ & $29 \%$ & $30 \%$ & $18 \%$ \\
\hline D & $6 \%$ & $11 \%$ & $10 \%$ & $0 \%$ & $20 \%$ & $0 \%$ \\
\hline$N$ & 18 & 9 & 20 & 7 & 10 & 17 \\
\hline
\end{tabular}


Table 4

Final Grade in Statistics Course by Mathematics Course Eligibility

\begin{tabular}{lccccc}
\hline Final Grade & Arithmetic & Pre algebra & $\begin{array}{c}\text { Elementary } \\
\text { algebra }\end{array}$ & $\begin{array}{c}\text { Intermediate } \\
\text { algebra }\end{array}$ & Total \\
\hline A & $0 \%$ & $14 \%$ & $44 \%$ & $25 \%$ & $26 \%$ \\
B & $67 \%$ & $43 \%$ & $44 \%$ & $38 \%$ & $44 \%$ \\
$\mathrm{C}$ & $33 \%$ & $14 \%$ & $11 \%$ & $38 \%$ & $22 \%$ \\
$\mathrm{D}$ & $0 \%$ & $29 \%$ & $0 \%$ & $0 \%$ & $7 \%$ \\
\hline $\mathrm{N}$ & 3 & 7 & 9 & 8 & 27 \\
\hline
\end{tabular}

The data in Table 4 show that students from a range of incoming mathematics levels in fall 2010 were successful in the statistics course in spring 2011 , with no clear pattern of students with higher incoming mathematics levels being more successful. Two-Course Sequence Success for Initial Cohort

Of the initial cohort of 29 , a total of 25 students successfully completed both courses--pre-statistics and statistics--resulting in an overall sequence completion rate of $86 \%$. Students from a range of incoming mathematics levels successfully completed the two-course sequence. Ten students began fall 2010 at the lowest mathematics levels, i.e. eligible to enroll in arithmetic or pre algebra. Of the ten, $80 \%(n=8)$ completed both courses with a grade of $\mathrm{C}$ or higher. In comparison, of the 19 students with eligibility for either elementary or intermediate algebra, 17 successfully completed both courses--an $89 \%$ success rate. 
Of the initial cohort, nearly all students $(n=28)$ were students of colorprimarily Latina/o and African American. The overall success percentage for students of color was $86 \%(n=24)$. Females and males completed the sequence at a similar success rate $(85 \%$ and $89 \%$, respectively). Younger students were somewhat more successful: $90 \%$ of those under 20 succeeded compared to $78 \%$ of students 20 years old or older.

Several students $(n=6)$ improved their grades from the first semester to the second. For example, three students received a B in the first semester pre-statistics class, but improved to an A in the statistics class. Four students showed grades that declined from the first to the second semester. For example, two students earned a B in the first semester but dropped to a $\mathrm{C}$ in the second semester. Most students $(n=17)$ maintained the same grade from one semester to the next.

Perhaps the most striking result corresponds to Puente, shown in Table 5. All 17 students concurrently enrolled in Puente successfully completed both semesters with a $\mathrm{C}$ or higher - compared to $67 \%$ of those not enrolled in Puente. In other words, all four students who did not complete (two withdrawing the first semester, and two earning Ds the second semester) were not enrolled in Puente. While the small $N$ should be kept in mind, this difference was statistically significant. 
Table 5

Course and Sequence Success by Puente Status

\begin{tabular}{|c|c|c|c|c|c|c|}
\hline & \multicolumn{2}{|c|}{ Fall 2010} & \multicolumn{2}{|c|}{ Spring 2011} & \multicolumn{2}{|c|}{ Full Sequence } \\
\hline & Puente & $\begin{array}{c}\text { Non- } \\
\text { Puente }\end{array}$ & Puente & $\begin{array}{c}\text { Non- } \\
\text { Puente }\end{array}$ & Puente & $\begin{array}{c}\text { Non- } \\
\text { Puente }\end{array}$ \\
\hline Successful & $100 \%$ & $83 \%$ & $100 \%$ & $80 \%$ & $100 \%$ & $67 \%$ \\
\hline Not Successful & $0 \%$ & $17 \%$ & $0 \%$ & $20 \%$ & $0 \%$ & $33 \%$ \\
\hline N & 17 & 12 & 17 & 10 & 17 & 12 \\
\hline
\end{tabular}

Fisher's Exact for outcome variable Full Sequence: $p=0.0208$

Additional analysis regarding students' average GPA for the sequence (average of the two course grades) found differences between Puente and Non-Puente students which approached statistical significance when Ws were treated as zeros. The Wilcoxon Rank Sums test showed $p=0.1064$ for the two-sided $t$-test approximation. Additionally, the Kruskal-Wallis test was statistically significant at $p=0.0908$. To examine the degree to which the two Withdrawals by Non-Puente students from the initial semester were affecting the statistical analysis, these two records were removed and both tests were re-run. After removing the Ws, the Wilcoxon Rank Sums and Kruskal-Wallis tests no longer showed statistically significant differences between the Puente and Non-Puente groups. (The tests showed $p=0.3178$ and $p=0.2962$ respectively) This is consistent with earlier findings that students not in Puente earned more As (Tables 1 and 3); however, students in Puente earned more Bs and Cs, and 
overall were more likely to complete both courses.

\section{CAOS Results at Sequence Culmination}

At the end of the second semester, StatMode students were assessed using a nationally-normed exam--the Comprehensive Assessment of Outcomes for a first course in Statistics (CAOS). The instructor incorporated 26 CAOS questions, 25 of

which she divided into two broad learning domains: (a) data exploration and descriptive statistics and (b) probability and inference. The $26^{\text {th }}$ question related to a third learning domain related to modeling. Since it was the sole CAOS question included from that domain, the question was excluded from this analysis. Also, additional questions designed by the instructor followed the CAOS questions in both Parts 1 and 2. These instructor-designed questions were also excluded from this analysis.

Student performance on the 25 questions was examined. Students included those 25 who began with the instructor in fall 2010 , completed the fall semester, and reenrolled with the instructor in spring 2011. Two students who took statistics in spring 2011 are excluded due to enrollment in different sections of statistics. While these students did successfully complete the introductory, college-level statistics course, they did not participate in the same final exam.

Regarding testing conditions, although StatMode students were allowed to retake sections of the exam within the two hour exam period, only the students' first attempts are represented in the data included in this analysis. The instructor used this 
approach to promote "productive persistence." It is worth noting that many students did retake the exam sections. For example 21 out of 25 students retook Part 1 a second time. Many (16) took Part 1 a third time. It is possible that the fact that students knew they could retake the exam artificially suppressed their performance on their first take. Moreover, the instructor noted that student performance on final exams is not always the best representation of their learning. Despite these caveats, the data in this section show that StatMode students performed comparably to an unmatched, more privileged national sample, described next.

The national sample was comprised of 1,470 students from 39 classes at 33 institutions in 21 different U.S states. Of the 33 institutions, $82 \%$ were four-year institutions; just $18 \%$ were community colleges. Of the 39 sections, $41 \%$ had college algebra or calculus as a prerequisite. Of the $1470,74 \%$ of the students were white. Cronbach's alpha for this sample was .82.

Figures 2 and 3 show the percent of students who answered each CAOS question answered correctly, as well as the average correct responses to all questions in the section (i.e. mean correct). Figure 2 corresponds to the first learning domain of data exploration and descriptive statistics. Most of the questions in Part 1 included histograms and boxplots and posed questions about data distribution. Figure 3 corresponds to the second learning domain of probability and inference. A few CAOS questions will be highlighted in the following section. For additional detailed 
information about CAOS items, see Appendix A in DelMas, Garfield, Ooms, and Chance, 2007.

\begin{tabular}{|c|c|c|c|c|}
\hline \multirow{2}{*}{$\begin{array}{c}\text { PART 1: } \\
\text { CAOS Item } \\
\text { Number }\end{array}$} & \multicolumn{2}{|c|}{$\begin{array}{c}15 \text { Instructor-Selected } \\
\text { Questions }\end{array}$} & \multicolumn{2}{|c|}{$\begin{array}{c}8 \text { Higher-Discrimination } \\
\text { Questions }\end{array}$} \\
\hline & $\begin{array}{l}\text { StatMode } \\
\text { Students }\end{array}$ & $\begin{array}{l}\text { National } \\
\text { Sample }\end{array}$ & $\begin{array}{l}\text { StatMode } \\
\text { Students }\end{array}$ & $\begin{array}{c}\text { National } \\
\text { Sample }\end{array}$ \\
\hline 1 & 32.0 & 74.1 & & \\
\hline 2 & 56.0 & 56.0 & & \\
\hline 3 & 64.0 & 72.4 & 64.0 & 72.4 \\
\hline 4 & 64.0 & 63.4 & 64.0 & 63.4 \\
\hline 5 & 76.0 & 69.8 & 76.0 & 69.8 \\
\hline 6 & 48.0 & 29.0 & 48.0 & 29.0 \\
\hline 9 & 0.0 & 28.9 & 0.0 & 28.9 \\
\hline 10 & 52.0 & 31.5 & 52.0 & 31.5 \\
\hline 11 & 72.0 & 89.0 & & \\
\hline 12 & 88.0 & 86.1 & & \\
\hline 13 & 88.0 & 74.1 & 88.0 & 74.1 \\
\hline 14 & 92.0 & 52.8 & 92.0 & 52.8 \\
\hline 15 & 84.0 & 50.7 & & \\
\hline 33 & 8.0 & 41.2 & & \\
\hline 18 & 36.0 & 80.0 & & \\
\hline $\begin{array}{l}\text { Mean } \\
\text { Correct }\end{array}$ & 57.3 & 59.9 & 60.5 & 52.7 \\
\hline
\end{tabular}

Figure 2. Percentage of correct responses for questions about data exploration and descriptive statistics.

Figure 2 shows that StatMode students performed roughly similar to the national sample for Part 1, consisting of 15 CAOS questions related to data exploration and descriptive statistics. On Part 1, StatMode students answered $57 \%$ of questions 
correctly, compared to $60 \%$ to the national sample. The right columns show the data when only those questions with higher discrimination levels $(>.35)$ are included. With this refinement, StatMode students outperformed the national sample. On average StatMode students answered $61 \%$ of higher-discrimination questions in Part 1 correctly, compared to $53 \%$ for students from the national sample.

Of the eight higher-discrimination questions in Part 1, StatMode students outperformed the national sample on five questions. StatMode students dramatically underperformed the national sample on only one item. Item 9, which pertained to a boxplot whisker, also elicited the fewest correct answers from the national sample. The CAOS developers described this item as testing student's "[u]nderstanding that boxplots do not provide estimates for percentages of data above or below values except for the quartiles" (DelMas, Garfield, Ooms, \& Chance, 2007, p. 54). StatMode students performed particularly well on CAOS item 14. This item tests students" "[a] bility to correctly estimate and compare standard deviations for different histograms.

Understands lowest standard deviation would be for a graph with the least spread (typically) away from the center" (DelMas, Garfield, Ooms, \& Chance, 2007, p. 55). Analyses of Part 1 found no statistically significantly relationships between CAOS scores and Puente status. Puente students scored 59\% and Non-Puente 54\% on all 15 questions. On high-discrimination questions, Puente students scored $63 \%$ versus $56 \%$ for Non-Puente. 


\begin{tabular}{|c|c|c|c|c|}
\hline \multirow{2}{*}{$\begin{array}{c}\text { PART 2: } \\
\text { CAOS Item } \\
\text { Number }\end{array}$} & \multicolumn{2}{|c|}{$\begin{array}{c}10 \text { Instructor-Selected } \\
\text { Questions }\end{array}$} & \multicolumn{2}{|c|}{$\begin{array}{c}5 \text { Higher-Discrimination } \\
\text { Questions }\end{array}$} \\
\hline & $\begin{array}{l}\text { StatMode } \\
\text { Students }\end{array}$ & $\begin{array}{l}\text { National } \\
\text { Sample }\end{array}$ & $\begin{array}{l}\text { StatMode } \\
\text { Students }\end{array}$ & $\begin{array}{l}\text { National } \\
\text { Sample }\end{array}$ \\
\hline 16 & 48.0 & 33.0 & 48.0 & 33.0 \\
\hline 17 & 80.0 & 51.6 & 80.0 & 51.6 \\
\hline 19 & 52.0 & 67.9 & & \\
\hline 25 & 44.0 & 57.1 & 44.0 & 57.1 \\
\hline 26 & 60.0 & 60.1 & & \\
\hline 27 & 52.0 & 54.4 & 52.0 & 54.4 \\
\hline 28 & 24.0 & 49.4 & 24.0 & 49.4 \\
\hline 29 & 52.0 & 65.4 & & \\
\hline 30 & 20.0 & 47.5 & & \\
\hline 31 & 68.0 & 75.9 & & \\
\hline $\begin{array}{l}\text { Mean } \\
\text { Correct }\end{array}$ & 50.0 & 56.2 & 49.6 & 49.1 \\
\hline
\end{tabular}

Figure 3. Percentage of correct responses for questions about probability and inference.

On Part 2 (shown in Figure 3), StatMode students answered ten CAOS questions about probability and inference. StatMode students on average answered $50 \%$ of questions correctly, compared to $56 \%$ of the national sample. When just the five higher-discrimination questions are included, StatMode students perform roughly the same as the national average (50\% versus $49 \%$ ). Overall, StatMode students performed higher on two of the five higher-discrimination questions. StatMode students performed particularly well on item 17, "Understanding of expected patterns in sampling variability" (DelMas, Garfield, Ooms, \& Chance, 2007, p. 55). 
Analyses of Part 2 found no statistically significantly relationships between CAOS scores and Puente status. Puente students scored $50 \%$ and Non-Puente $50 \%$ on all ten questions. On high-discrimination questions, Puente students scored $49 \%$ versus $50 \%$ for Non-Puente.

\section{Hope Scale Results for Interviewees}

StatMode interviewees $(N=11)$ completed the Adult Dispositional Hope Scale (ADHS). According to its developers, the ADHS has a Cronbach's alpha ranging from .74 to .84 (Snyder, 1991). Interviewees responded to eight statements across two domains (agency and pathways). Four statements assessed students' sense of agency, i.e. individual determination to meet goals. A sample agency statement is "I energetically pursue my goals." Four statements assessed an individual's ability to produce the means for attaining the goals, i.e. create or identify pathways to goal attainment. A sample pathways question is "Even when others get discouraged, I know I can find a way to solve the problem."

All eight statements agency and pathways statements were framed positively such that a high score reflected a high sense of agency or pathways. Students rated each statement with "definitely true" (4.0), "true" (3.0), "false" (2.0), or "definitely false" (1.0). For each domain, agency and pathways, the maximum possible score is 16.0, based on the four-point scale, summing across four statements. The total hope score is determined by adding the two domains, with a maximum possible score of 32.0 . A 
score of 24.0 or higher indicates "high hope" (Snyder, 1994).

StatMode interviewees generally agreed with all four statements in both agency and pathways categories, indicating either true (3.0) or definitely true (4.0). Fewer than half of the students disagreed with any of the statements: four students indicated false or definitely false to one statement. As a result, all interviewees had high hope scores. All students, across all demographics, scored high: the young Latino/a students, the somewhat older Latino student (Manny), and the three African American women. Interviewees had a mean hope score of 27.5 , with individual scores ranging from 24.0 to 30.0 .

The ADHS instrument also contains four distracter statements. These four statements, interspersed within the instrument, are all framed negatively. The statements include references to fatigue and worrying, with a high score indicating a high degree of frequency. Student rated the distracter statements low, tending to disagree with statements such as "I feel tired most of the time." The maximum possible score was 16.0 (based on a four-point scale across four statements). The overall mean for all eleven students combined was 7.5 , with individual scores ranging from 4.0 to 10.0. The fact that students responding differently on the distracter statements, compared to the pathways and agency questions, indicates a thoughtful response to the instrument.

Table 6 shows interviewee responses for pathways, for agency, and for the 
combined total. While slightly different on the subscales, the Puente and Non-Puente subgroups had similar totals, rounding to 27 and 28, respectively. Compared to the aforementioned "high hope" cutoff of 24, these students evidenced high hope. An additional comparison is provided in Table 6. Snyder (1991) surveyed college students for several years and found mean hope cores ranging from 25 to 26 (lowest and highest years respectively).

Table 6

Hope Scores for StatMode Interviewees and Comparison Groups

\begin{tabular}{|c|c|c|c|c|}
\hline & $\mathrm{N}$ & Pathways & Agency & Total $^{\mathrm{b}}$ \\
\hline & \multicolumn{4}{|c|}{ StatMode Interviewees } \\
\hline All Interviewees & 11 & 13.9 & 13.6 & 27.5 \\
\hline Non-Puente Subgroup & 4 & 14.5 & 13.3 & 27.8 \\
\hline \multirow[t]{2}{*}{ Puente Subgroup } & 7 & 13.6 & 13.9 & 27.4 \\
\hline & \multicolumn{4}{|c|}{ Comparison Groups } \\
\hline College Students - Highest Year ${ }^{a}$ & 955 & 12.8 & 12.8 & 25.6 \\
\hline College Students - Lowest Year ${ }^{a}$ & 875 & 12.5 & 12.6 & 25.1 \\
\hline
\end{tabular}

Note: Maximum Total Score $=32.0$.

${ }^{\text {a }}$ Published by Snyder (1991).

ber Snyder (1994) score >= 24.0 indicates "high hope."

\section{Summary and Synthesis}

Most StatMode students completed the initial pre-statistics mathematics course 
successfully, persisted to the transfer-level statistics course, and successfully completed transfer-level statistics. Overall, $86 \%$ of the original cohort of 29 students completed the full, two-semester sequence. All but one of the students were students of colorpredominately African American and Latina/o. Gender, age group, and incoming mathematics eligibility level were not significantly related to the course and sequence outcome variables.

While both Puente and Non-Puente students were generally successful in completing the two-course sequence, findings suggest that Puente students were more likely to remain in StatMode. Specifically, three different outcome variables showed statistically significant differences, or differences which approached statistical significance. The first semester grade distribution differed between Puente and NonPuente students: Non-Puente students received more As, Cs, and Ws; Puente students received more Bs. The overall two-course sequence completion rate defined in terms of yes (completed with a $\mathrm{C}$ or higher) or no (D, F or W) was statistically significant by Puente and Non-Puente status, with a larger proportion of Puente students (100\%) completing the sequence. Moreover, this finding approached statistical significance when using the Wilcoxon Rank-sum test to evaluate combined GPA across the two terms - as long as withdrawals were included as a zero GPA. Once withdrawals were excluded, the difference between the GPAs of Puente and Non-Puente students was no longer statistically significant. 
Quantitative findings suggest that StatMode students performed comparably to, and perhaps somewhat better than, the national average on the Comprehensive Assessment of Outcomes for a first course in Statistics (CAOS). Scores were assembled for two learning domains-(a) data exploration and descriptive statistics and (b) probability and inference. Based on questions selected for discrimination $>.35$, StatMode students from the initial cohort scored somewhat better than the national average within the first domain, averaging $61 \%$ of questions answered correctly, compared to $53 \%$ for students from the national sample. For the second, probability domain, StatMode students had a mean performance of $50 \%$, compared to the national mean of $49 \%$. Based on this data, StatMode students not only completed the twocourse sequence at high rates, but students also performed comparably on a post-test when compared to national peers who were primarily white, primarily from four-year institutions, and most of whom were required to have higher mathematics prerequisites before beginning the statistics course.

Finally, the StatMode students who were interviewed $(N=11)$ were asked to complete the Adult Dispositional Hope Scale (ADHS). Students scored relatively high on both the pathways and agency parameters of the ADHS. Students met the criteria determined by the ADHS developer for having "high hope." 